\title{
Repositioning Lopinavir, an HIV Protease Inhibitor, as a Promising Antifungal Drug: Lessons Learned from Candida albicans-In Silico, In Vitro and In Vivo Approaches
}

\author{
André L. S. Santos ${ }^{1,2, *}$, , Lys A. Braga-Silva ${ }^{1,2}$, Diego S. Gonçalves ${ }^{1,2}{ }^{\circledR}$, Lívia S. Ramos ${ }^{1}$, Simone S. C. Oliveira ${ }^{1}$,
} Lucieri O. P. Souza ${ }^{1}$, Vanessa S. Oliveira ${ }^{3}$, Roberto D. Lins ${ }^{3}{ }^{\mathbb{D}}$, Marcia R. Pinto ${ }^{4}$, Julian E. Muñoz ${ }^{5}{ }^{(}$, Carlos P. Taborda ${ }^{6,7} \mathbb{1}$ and Marta H. Branquinha ${ }^{1, * \mathbb{D}}$

check for updates

Citation: Santos, A.L.S.;

Braga-Silva, L.A.; Gonçalves, D.S.; Ramos, L.S.; Oliveira, S.S.C.; Souza, L.O.P.; Oliveira, V.S.; Lins, R.D.; Pinto, M.R.; Muñoz, J.E.; et al. Repositioning Lopinavir, an HIV Protease Inhibitor, as a Promising Antifungal Drug: Lessons Learned from Candida albicans-In Silico, In Vitro and In Vivo Approaches. J. Fungi 2021, 7, 424. https://doi.org/10.3390/jof7060424

Academic Editor: Renátó Kovács

Received: 30 April 2021

Accepted: 25 May 2021

Published: 28 May 2021

Publisher's Note: MDPI stays neutral with regard to jurisdictional claims in published maps and institutional affiliations.

Copyright: (c) 2021 by the authors. Licensee MDPI, Basel, Switzerland. This article is an open access article distributed under the terms and conditions of the Creative Commons Attribution (CC BY) license (https:/ / creativecommons.org/licenses/by/ $4.0 /)$.
1 Laboratório de Estudos Avançados de Microrganismos Emergentes e Resistentes (LEAMER), Departamento de Microbiologia Geral, Instituto de Microbiologia Paulo de Góes (IMPG), Universidade Federal do Rio de Janeiro (UFRJ), Rio de Janeiro 21941-901, Brazil; lysmonica@yahoo.com.br (L.A.B.-S.); fusariumsp@gmail.com (D.S.G.); liviaramos2@yahoo.com.br (L.S.R.); simonesantiagorj@yahoo.com.br (S.S.C.O.); lucieri@micro.ufrj.br (L.O.P.S.)

2 Programa de Pós-Graduação em Bioquímica (PPGBq), Instituto de Química (IQ), Universidade Federal do Rio de Janeiro (UFRJ), Rio de Janeiro 21941-909, Brazil

3 Instituto Aggeu Magalhães, Fundação Oswaldo Cruz, Recife 50740-465, Brazil; vanessa.silvao@ufpe.br (V.S.O.); roberto.lins@cpqam.fiocruz.br (R.D.L.)

4 Departamento de Microbiologia e Parasitologia, Instituto Biomédico, Universidade Federal Fluminense (UFF), Niterói 24210-130, Brazil; mpinto@id.uff.br

5 MICROS Group, Medicine Traslacional Institute, School of Medicine and Health Sciences, Universidad del Rosario, Bogotá 111221, Colombia; juliane.munoz@urosario.edu.co

6 Departamento de Microbiologia, Instituto de Ciências Biomédicas, Universidade de São Paulo (USP), São Paulo 05508-060, Brazil; taborda@usp.br

7 Laboratório de Micologia Médica-LIM53/IMTSP, Universidade de São Paulo (USP), São Paulo 05508-000, Brazil

* Correspondence: andre@micro.ufrj.br (A.L.S.S.); mbranquinha@micro.ufrj.br (M.H.B.); Tel.: +55-21-3938-0366 (A.L.S.S.)

Abstract: The repurposing strategy was applied herein to evaluate the effects of lopinavir, an aspartic protease inhibitor currently used in the treatment of HIV-infected individuals, on the globally widespread opportunistic human fungal pathogen Candida albicans by using in silico, in vitro and in vivo approaches in order to decipher its targets on fungal cells and its antifungal mechanisms of action. Secreted aspartic proteases (Saps) are the obviously main target of lopinavir. To confirm this hypothesis, molecular docking assays revealed that lopinavir bound to the Sap2 catalytic site of C. albicans as well as inhibited the Sap hydrolytic activity in a typically dose-dependent manner. The inhibition of Saps culminated in the inability of C. albicans yeasts to assimilate the unique nitrogen source (albumin) available in the culture medium, culminating with fungal growth inhibition $\left(\mathrm{IC}_{50}=39.8 \mu \mathrm{M}\right)$. The antifungal action of lopinavir was corroborated by distinct microscopy analyses, which evidenced drastic and irreversible changes in the morphology that justified the fungal death. Furthermore, our results revealed that lopinavir was able to (i) arrest the yeasts-into-hyphae transformation, (ii) disturb the synthesis of neutral lipids, including ergosterol, (iii) modulate the surface-located molecules, such as Saps and mannose-, sialic acid- and $\mathrm{N}$-acetylglucosamine-containing glycoconjugates, (iv) diminish the secretion of hydrolytic enzymes, such as Saps and esterase, (v) negatively influence the biofilm formation on polystyrene surface, (vi) block the in vitro adhesion to epithelial cells, (vii) contain the in vivo infection in both immunocompetent and immunosuppressed mice and (viii) reduce the Sap production by yeasts recovered from kidneys of infected animals. Conclusively, the exposed results highlight that lopinavir may be used as a promising repurposing drug against $C$. albicans infection as well as may be used as a lead compound for the development of novel antifungal drugs.

Keywords: Candida albicans; drug repurposing; HIV protease inhibitors; secreted aspartic proteases; lopinavir; virulence; adhesion; biofilm; morphogenesis; animal infection 


\section{Introduction}

Mucosal candidiasis, including oropharyngeal, esophageal and vaginal candidiasis, is common among human immunodeficiency virus (HIV)-infected individuals, and the risk is considered to be higher in patients with $\mathrm{CD}^{+} \mathrm{T}$ lymphocytes counts of $<200$ cells $/ \mathrm{mm}^{3}$ and high plasma HIV RNA loads [1-8]. Due to its relevance, oropharyngeal candidiasis is a sentinel indicator of immunodeficiency and HIV disease progression [9]. Deep-seated candidal infections are an important cause of morbidity and mortality in immunocompromised individuals and severely ill patients [7]. Candida albicans represents the most common causative agent of oral, vaginal and disseminated candidiasis [4,7]. Although the fungus is a harmless commensal in healthy individuals, C. albicans can rapidly proliferate, invade tissues and cause symptomatic mucosal lesions in immunocompromised persons. C. albicans is the main widespread human fungal pathogen, which is commonly recovered from hospital settings around the globe. C. albicans possesses a genomic plasticity that directly reflects in a metabolic diversity and in the production of a plethora of virulence attributes, which helps it to colonize and adapt to several distinct physicochemical environments as well as to escape from host immune responses $[7,8]$. These virulence attributes include the (i) surface adhesin molecules (e.g., mannoproteins and glycoconjugates); (ii) reversible transition between unicellular yeast cells into filamentous forms (morphogenesis process); (iii) ability to form robust biofilm on both inert and living surfaces and (iv) secretion of extracellular hydrolytic enzymes (e.g., proteases and lipases) $[7,8]$.

Remarkable findings from clinical trials with HIV-infected populations have shown a decrease in oral candidal infection as well as other classical oral manifestations of HIV infection [9-12]. Oral candidiasis decrease was first observed when antiretrovirals belonging to the protease inhibitor (PI) class were included amongst the drugs used to treat HIV infection in the well-known highly active antiretroviral therapy (HAART), and this mucocutaneous infection is nowadays only rarely observed in treated patients [9-12]. Considered a very effective therapy, HAART decreases the HIV viral load and leads to the increase in $\mathrm{CD}^{+} \mathrm{T}$ lymphocyte counts and the partial recovery of $\mathrm{T}$ cell responses against recall antigens, as well as stimulates the survival and activation of neutrophil, monocyte, dendritic and endothelial cells [13-16], causing an improvement in the immunity and a decrease in the incidence of opportunistic infections $[17,18]$. For instance, the treatment with saquinavir leads to the resolution of mucosal candidiasis in a patient refractory to the treatment with fluconazole [19]. However, controversy exists concerning whether the decrease in frequency of candidiasis in HIV patients is due to an improvement in the patient's immune status, or to an effect of the HIV PIs on the colonization capacity of C. albicans, or to an antifungal effect exerted by HIV PIs. This hypothesis was based on clinical observations in which HIV-positive subjects receiving HAART manifest a marked decrease in the incidence of oral candidiasis, sometimes soon after initiation of therapy and well before the number of $\mathrm{CD} 4^{+} \mathrm{T}$ lymphocytes recover [20]. Subsequently, several lines of evidence have proposed that the HIV PIs have direct inhibitory effects on C. albicans aspartic proteases (designated as secreted aspartic proteases-Saps, which are key virulence factors), culminating in the reduction of fungal growth [21]. The C. albicans Saps are thought to play a multimodal role in the infectious process; so, the development of Sap inhibitors for the treatment of candidiasis thus appears to be a valid strategy [21].

The antifungal activity of the first-generation HIV PIs (e.g., ritonavir, saquinavir, indinavir and ritonavir) was demonstrated in in vitro and in in vivo studies, particularly against yeasts (e.g., Candida spp. and Cryptococcus neoformans) and some filamentous fungi (e.g., Fonsecaea pedrosoi and Pneumocystis jirovecii) [21,22]. However, contradictory results regarding the antifungal action of HIV PIs have been published in the literature. A simple explanation by those ambiguous results is based on the different methodologies that were employed; for example, to detect the antifungal activity in which distinct culture medium, time of fungal-drug exposure, drug concentration, number of fungi tested and method to reveal the experiment. In addition, the second generation of HIV PIs presents better pharmacological (pharmacokinetics/pharmacodynamics) parameters. These novel 
HIV PI treatment regimens attained preferred status because they have clinical trial data support for their efficacy, durability of effect, tolerability and ease of use [23]. For instance, Otto et al. [24] described a case of cryptococcal meningitis associated with an immune reconstitution inflammatory syndrome (IRIS) in a ten-year-old HIV-infected child prior to the switch from the first-line to second-line HAART (abacavir-lamivudine efavirenz to zidovudine-lamivudine-lopinavir/ritonavir) due to the virological failure. So, the repurposing of HIV PIs as antifungal agents is a valid and contemporary strategy.

In the present work, lopinavir, an HIV PI commonly used in the clinical arena to treat HIV-infected patients, was evaluated against the ubiquitous opportunistic human fungal pathogen C. albicans by multimodal strategies using in silico, in vitro and in vivo experimental approaches in order to decipher its targets on fungal cells and its antifungal mechanisms of action.

\section{Materials and Methods}

\subsection{Chemicals}

Lopinavir was obtained from the National Institutes of Health (NIH) and dissolved in dimethylsulfoxide (DMSO) to obtain a final concentration of $20 \mathrm{mM}$. Bovine serum albumin (BSA), pepstatin A, ergosterol, lanosterol, fluorescein isothiocyanate (FITC)-labeled secondary antibody, FITC-Concanavalin A (Con A), FITC-Limax flavus agglutinin (LFA), FITC-wheat germ agglutinin (WGA), Calcofluor white, crystal violet, menadione, 2,3-bis (2-methoxy-4-nitro-5-sulfophenyl)-5-[(phenylamino) carbonyl]-2H-tetrazolium hydroxide (XTT), formalin, Dulbecco's Modified Eagle's Medium (DMEM), Giemsa and cyclophosphamide were purchased from Sigma-Aldrich (St. Louis, MO, USA). Yeast carbon base (YCB) and brain and heart infusion (BHI) media were obtained from HiMedia Laboratories Ltd. (Mumbai, India). Fetal bovine serum (FBS) was purchased from Cultilab (São Paulo, Brazil). Ketamine and xylazine were obtained from União Química Farmacêutica (São Paulo, Brazil). Reagents used in microscopy, electrophoresis and buffer components were purchased from Amersham (Little Chalfont, United Kingdom). All other reagents were of analytical grade.

\subsection{Fungal Strain and Growth Conditions}

Candida albicans strain 11 was previously isolated by our research group from the blood of an HIV-positive, 46-year-old male. This strain presents a trailing phenomenon in terms of an in vitro susceptibility test with azoles, and expresses a high amount of both cell-associated and extracellular aspartic-type proteases, particularly Sap2 (Figure S1) [25]. In all experiments, fungal cells were cultivated on $1.2 \%$ YCB supplemented with $0.1 \%$ BSA, $\mathrm{pH}$ 5.0, and grown at $37^{\circ} \mathrm{C}$ for $48 \mathrm{~h}$ under slight agitation (100 rpm), which is a well-known Sap-inducing condition [25-27]. Cell growth was estimated by counting the yeasts in a Neubauer chamber.

\subsection{Effects of Lopinavir on C. albicans Sap2: In Silico Approach}

Molecular docking assays of the standard ligand A70450, a synthetic hexapeptide analogue to pepstatin A (Figure S2), and lopinavir to the active site of the C. albicans Sap2 protein were carried out using the Autodock Vina 1.1.2 program [28]. The atomic coordinates for Sap2, complexed with its ligand, were taken from the Protein Data Bank (PDB ID 1EAG) [29]. The ligand coordinates were removed and the $\mathrm{pKa}$ of each titratable residue estimated by the Propka 3.0 program [30]. Except for $\mathrm{D}_{32}$ that presented an estimated $\mathrm{pKa}$ of 9.88, all the remaining residues showed no significant shifts from their model reference values. Due to the uncertainty regarding the protonation states of the nitrogen atoms in lopinavir, two protonation states for lopinavir were considered (Figure S2). Atomic charges for protein and ligands were assigned using the Gasteiger method in the ADT 1.5.4 program [31]. A grid box, encompassing the center of the mass of residues $D_{32}, D_{218}$ and $G_{85}$ of dimensions $22 \times 22 \times 22 \AA$, was used for the molecular docking. These residues were chosen due to their identified hydrogen-bond interactions with A70450. A total of 9 binding 
modes were generated in each case, with an estimated $3 \mathrm{kcal} / \mathrm{mol}$ maximum difference between the best and worst binding modes. The associated error of the method is typically $1-2 \mathrm{kcal} / \mathrm{mol}$. Therefore, the energetic criterion, the raking (most prevalent conformation) and the interactions of the ligand with the catalytic dyad and $G_{85}$ were analyzed.

\subsection{Effects of Lopinavir on Saps: In Vitro Assay}

In order to obtain the conditioned supernatant of C. albicans cells, which is rich in Saps (Figure S1), the $96 \mathrm{~h}$-old culture was harvested by centrifugation at $4000 \times g$ for $10 \mathrm{~min}$ at $4{ }^{\circ} \mathrm{C}$, and the supernatant was filtered in a $0.22-\mu \mathrm{m}$ membrane (Millipore, São Paulo, Brazil) and used to measure the extracellular protease activity. Proteolytic activity was measured spectrophotometrically using the substrate BSA, according to the method described by Buroker-Kilgore and Wang [32]. Initially, the supernatant fluid was incubated for $30 \mathrm{~min}$ at $37^{\circ} \mathrm{C}$ in the presence or in the absence of $10 \mu \mathrm{M}$ pepstatin A (a classical aspartic PI) or lopinavir at different concentrations ranging from 6.25 to $200 \mu \mathrm{M}$. For assaying the remaining proteolytic activity, BSA $(0.5 \mathrm{mg} / \mathrm{mL}), 20 \mathrm{mM}$ sodium citrate $(\mathrm{pH} 4.0)$ and $40 \mu \mathrm{L}$ of supernatant fluid were added to a microcentrifuge tube $(350 \mu \mathrm{L})$ and incubated for $2 \mathrm{~h}$ at $37^{\circ} \mathrm{C}$. After this incubation, three aliquots $(100 \mu \mathrm{L}$ each $)$ of the reaction mixture were transferred to wells on a microtiter plate containing $50 \mu \mathrm{L}$ of water and $100 \mu \mathrm{L}$ of a Coomassie solution (0.025\% Coomassie brilliant blue G-250, 11.75\% ethanol and 21.25\% phosphoric acid). After 10 min to allow dye binding, the plate was read on a Thermomax Molecular Device microplate reader at an absorbance of $595 \mathrm{~nm}$.

\subsection{Effects of Lopinavir on Growth}

In this set of experiments, two distinct approaches were performed to study the effects of lopinavir on C. albicans when grown in YCB-BSA medium: (i) different densities of yeasts $\left(10^{2}\right.$ to $10^{6}$ cells) were incubated with lopinavir at $50 \mu \mathrm{M}$, and (ii) $10^{3}$ yeasts were treated with different lopinavir concentrations (3.125 to $100 \mu \mathrm{M})$. All the systems were incubated for $20 \mathrm{~h}$ at $37^{\circ} \mathrm{C}$ with slight agitation (100 rpm). Subsequently, fungal cells were washed three times in phosphate-buffered saline (PBS, pH 7.0) and re-inoculated in BHI medium without drugs, to measure the colony-forming units (CFUs) [33]. The solvent (DMSO) has also been tested for its possible ability to inhibit cellular growth, presenting negative results. A control was also made replacing lopinavir with PBS.

2.6. Lopinavir Treatment: Looking for Possible Molecular Targets in C. albicans Cells Other Than Saps and Role in Crucial Physiopathology Events

For all the subsequent experiments (except when discriminated), $10^{6}$ yeast cells were treated (or not) with lopinavir (at both 100 and $200 \mu \mathrm{M}$ ) for $20 \mathrm{~h}$ in order to detect the influence of this HIV PI on the (i) morphological/ultrastructural architecture; (ii) morphogenesis; (iii) expression of surface molecules; (iv) production of extracellular enzymes; (v) interaction with abiotic (polystyrene) and biotic (epithelial cells) surfaces and (vi) infection using murine models.

\subsection{Effects of Lopinavir on Morphometrical Parameters and Morphology}

Untreated and lopinavir-treated fungal cells were fixed with $4 \%$ paraformaldehyde at $4{ }^{\circ} \mathrm{C}$ for $30 \mathrm{~min}$ and then analyzed in a flow cytometer (FACSCalibur; BD Bioscience, La Jolla, CA, USA) equipped with a 15-mW argon laser emitting at $488 \mathrm{~nm}$. Each experimental population was mapped (10,000 events) using a two-parameter histogram of forwardangle light scatter (FSC) versus side scatter (SSC) in order to evaluate size and granularity, respectively. In parallel, fungal cells were incubated with $100 \mu \mathrm{L}$ Calcofluor white solution $(1 \mathrm{mg} / \mathrm{mL})$ and incubated for $5 \mathrm{~min}$ at room temperature. Then, cells were washed three times with PBS and resuspended in $100 \mu \mathrm{L}$ of the same buffer. Five microliters of the stained cell suspension were spotted onto a glass slide and visualized under a bright field and UV/DAPI using an Observer Z1 (Zeiss, Jena, Germany) fluorescence microscope. Images were acquired with a Color View AxioCam MRm digital camera. 


\subsection{Effects of Lopinavir on Ultrastructural Architecture}

In this set of experiments, both transmission (TEM) and scanning (SEM) electron microscopies were performed in order to detect fungal ultrastructural changes. For TEM assay, fungal cells were fixed with a solution containing $2.5 \%$ glutaraldehyde, $4 \%$ paraformaldehyde and $10 \mathrm{mM} \mathrm{CaCl} 2$ in $0.1 \mathrm{M}$ cacodylate buffer ( $\mathrm{pH} 7.2$ ) for $1 \mathrm{~h}$ at $25^{\circ} \mathrm{C}$. Then, fungal cells were washed with the same buffer and post-fixed for $1 \mathrm{~h}$ in a solution containing $1 \%$ $\mathrm{OsO}_{4}$ and $0.8 \%$ potassium ferricyanide in cacodylate buffer. Finally, the cells were rinsed, dehydrated in a graded series of acetone and embedded in Spurr resin. Ultrathin sections were obtained, stained with uranyl acetate and lead citrate and examined using a JEOL 1200 EX transmission electron microscope [34]. For SEM analyses, fungal cells were washed in cacodylate buffer $(0.1 \mathrm{M})$ and fixed for $2 \mathrm{~h}$ at room temperature in the same buffer containing $2.5 \%$ glutaraldehyde. Then, fungi were post-fixed in $1 \% \mathrm{OsO}_{4}$ for $1 \mathrm{~h}$ at room temperature and adhered to poly-L-lysine-coated glass coverslips (0.1\%). Fungi were then washed three times with PBS and then dehydrated in increasing ethanol series $(30,50,70$, $80,95$ and $100 \%)$. After this step, the preparations were dried by the critical point method, mounted on aluminum supports and coated with gold-palladium. Electron micrographs were obtained from the Quanta 250 scanning electron microscope (FEI Company).

\subsection{Effects of Lopinavir on Morphogenesis}

The transformation of yeasts into germ tubes (morphogenesis process) was performed by incubating $10^{6}$ yeasts in $1 \mathrm{~mL}$ of FBS $[35,36]$ supplemented or not with different concentrations of lopinavir (varying from 12.5 to $200 \mu \mathrm{M}$ ). All the systems were incubated for $4 \mathrm{~h}$ at $37^{\circ} \mathrm{C}$ without agitation. At the end of the incubation period, samples were used for microscopic assessment of germ tube production in a Zeiss microscope (Zeiss). The percentage of germination was estimated by counting 100 fungal cells in a Neubauer chamber.

\subsection{Effects of Lopinavir on Neutral Lipids}

\subsubsection{Sterol Content}

Fungal cells were subjected to incubation with a chloroform:methanol mixture (2:1 $v / v$ ) in order to extract the lipids [37]. Precipitated material was removed by centrifugation, and the solution was then reduced to dryness under nitrogen. Following Folch partition [38], the sterol content of the lipid extract was analyzed by high-performance thin-layer chromatography (HPTLC) using a solvent mixture of hexane-ether-acetic acid $(80: 40: 2 v / v / v)$ and revealed a solution comprising $50 \mathrm{mg}$ of $\mathrm{FeCl}_{3}, 90 \mathrm{~mL}$ of water, $5 \mathrm{~mL}$ of acetic acid and $5 \mathrm{~mL}$ of $\mathrm{H}_{2} \mathrm{SO}_{4}$. The plate was heated to $100{ }^{\circ} \mathrm{C}$ for $5 \mathrm{~min}$, and the bands corresponding to sterols were then visualized and compared to sterol standards, ergosterol and lanosterol [39]. In order to quantify the ergosterol in the chromatogram more accurately, the plate was initially digitized, and the bands corresponding to the ergosterol migration were manually selected using the free selection tool provided by the Image J software. Band areas were then determined by repeating this process 3 times, to diminish the probability of errors in these estimations. Values of band area were further integrated with means of grey level in selected bands, generating densitometric values (which were expressed as arbitrary units-AU) that were used in the comparison between corresponding bands in the same chromatogram [40].

\subsubsection{Nile Red Staining}

Fungi were incubated with Nile red $(5 \mu \mathrm{g} / \mathrm{mL})$ in the dark for $30 \mathrm{~min}$ for the detection of lipid bodies, a place of accumulation of intracellular neutral lipids, by both fluorescence microscopy and flow cytometer assays. For fluorescence microscopy, the fungal cells were deposited in blade/coverslip systems and observed with a fluorescence microscope Zeiss Axioplan-D image D2. In the flow cytometry assay, the mapped population was analyzed for log red fluorescence using a single-parameter histogram, and the results were expressed as the percentage of fluorescent cells (\%FC) and mean of fluorescence intensity (MFI). 


\subsection{Effects of Lopinavir on Cell Wall-Located Surface Molecules}

In this set of fluorocytometric analyses, fungal cells were initially fixed in $4 \%$ paraformaldehyde for $1 \mathrm{~h}$, rinsed in PBS and then incubated for $1 \mathrm{~h}$ at room temperature in the presence of the following fluorescent agglutinins: FITC-Con A $(5 \mu \mathrm{g} / \mathrm{mL})$, FITC-WGA $(10 \mu \mathrm{g} / \mathrm{mL})$ and FITC-LFA $(25 \mu \mathrm{g} / \mathrm{mL})$, which recognize $\alpha$-D-mannosyl $/ \alpha$-D-glucosyl residues, $\mathrm{N}$-acetylglucosamine oligomers and $\mathrm{N}$-acetylneuraminic acid, respectively [41]. In addition, the anti-Sap1-3 polyclonal antibody raised against $C$. albicans (kindly provided by Dr. Nina Agabian, University of California, San Francisco, CA, USA), at 1:1000 dilution, was also tested to detect surface-located aspartic proteases (Saps). Fungi were washed in PBS and subsequently treated with the primary antibody followed by a $1 \mathrm{~h}$ incubation period with the FITC-secondary antibody. In parallel, fungal cells that had not been incubated with agglutinins or antibodies were also prepared in order to run as autofluorescence control systems. Finally, fungi were washed in PBS and analyzed by flow cytometry. Control cells were analyzed first in order to determine their autofluorescence and relative size. The mapped population (10,000 events) was analyzed for log green fluorescence by using a single-parameter histogram. The results were expressed by means of two parameters: \%FC and MFI.

\subsection{Effects of Lopinavir on Secreted Hydrolytic Enzymes}

Two major groups of hydrolytic enzymes produced by C. albicans cells were evaluated: proteases and lipases. Aspartic protease production was assayed using the albumin agar plate $(1.17 \%$ YCB medium supplemented with $0.2 \% \mathrm{BSA}, \mathrm{pH} 4.0)$ as previously described by Ruchel et al. [42]. The protease activity results in a clear zone around the colony, which corresponds to the hydrolysis of the BSA present in the medium. In parallel, the production of two distinct lipases, phospholipase and esterase, was also investigated. The determination of phospholipase activity was performed using an egg yolk agar plate $(1 \mathrm{M}$ $\mathrm{NaCl}, 5 \mathrm{mM} \mathrm{CaCl}_{2}$ and $8 \%$ sterile egg yolk emulsion, $\mathrm{pH} \mathrm{7.0)}$ according to Price et al. [43]. The esterase production was assayed using the Tween agar plate $(1 \mathrm{~g}$ of peptone, $0.5 \mathrm{~g}$ of $\mathrm{NaCl}, 0.01 \mathrm{~g}$ of $\mathrm{CaCl}_{2}$, pH 7.0, $1.5 \mathrm{~g}$ of agar and $100 \mathrm{~mL}$ of distilled water, which was autoclaved, then cooled to about $50{ }^{\circ} \mathrm{C}$, and $0.5 \mathrm{~mL}$ of autoclaved Tween were added) according to Aktas et al. [44]. In these methods, the hydrolysis of lipid substrates present in egg yolk or Tween results in the formation of a calcium complex with fatty acids released by the action of the secreted enzymes, resulting in a precipitation zone around the colony. The colony diameter (a) and the diameter of colony plus precipitation zone (b) were measured by a digital paquimeter. The enzymatic activities were expressed as $P z$ values $(a / b)$ as described by Price et al. [43]. According to this definition, low $P z$ values mean high enzymatic production, and, inversely, high $\mathrm{Pz}$ values indicate low enzymatic production.

\subsection{Effects of Lopinavir on Biofilm}

The effects of lopinavir were tested on different biofilm perspectives: (i) pre-treatment, when fungal cells ( $10^{6}$ yeasts) were pre-treated or not with lopinavir at 100 or $200 \mu \mathrm{M}$ for $20 \mathrm{~h}$ and then incubated for $48 \mathrm{~h}$ over a polystyrene substrate; (ii) joined treatment, when fungal cells were plated at the same time to adhere to the polystyrene substrate in the absence or in the presence of lopinavir $(100$ and $200 \mu \mathrm{M})$, and then the systems were incubated for $48 \mathrm{~h}$; and (iii) post-treatment, when fungal cells were first adhered to polystyrene for $48 \mathrm{~h}$, and then the mature biofilm was treated with lopinavir (100 and $200 \mu \mathrm{M}$ ) for an additional $20 \mathrm{~h}$. After all these protocols, the spent medium was aspirated, and non-adherent cells were removed by thoroughly washing the biofilms with PBS. Wells with media and no cells were included as blank wells. Finally, two biofilm parameters were analyzed: biomass and viability (metabolic activity). The biomass of the resultant biofilms was then assessed using the crystal violet assay [45]. Briefly, $100 \mu \mathrm{L}$ of $99 \%$ methanol were added to each well for $15 \mathrm{~min}$ to fix the biofilm, and then the supernatants were discarded. Microplates were air-dried, and then $100 \mu \mathrm{L}$ of crystal violet solution (1:50 from stock solution) were added to wells and incubated at room temperature for $20 \mathrm{~min}$. The extra 
dye was washed away with tap water, and then $150 \mu \mathrm{L}$ of acetic acid $33 \%$ were added to the wells. The absorbance was measured at $590 \mathrm{~nm}$ using a Thermomax Molecular Device microplate reader. In parallel, the viable cells in biofilm were assessed by the colorimetric assay that investigates the metabolic reduction of XTT to a water-soluble brown formazan product. In this sense, $100 \mu \mathrm{L}$ of the XTT/menadione solution $(4 \mathrm{mg}$ XTT in $10 \mathrm{~mL}$ prewarmed PBS were dissolved and supplemented by a $100 \mu \mathrm{L}$ menadione stock solution, which contained $55 \mathrm{mg}$ menadione in $100 \mathrm{~mL}$ acetone) were added to all wells and incubated in the dark at $37^{\circ} \mathrm{C}$ for $3 \mathrm{~h}$. The contents of the wells were transferred to microcentrifuge tubes and centrifuged at $4000 \times g$ for $5 \mathrm{~min}$. A total of $100 \mu \mathrm{L}$ of supernatant from each well was transferred to a new microplate, and the colorimetric changes were measured at $492 \mathrm{~nm}$ using a microplate reader [45].

\subsection{Effects of Lopinavir on In Vitro Interaction with Epithelial Cells}

Larynx carcinoma cells (HEp2), purchased from RJCB Collection (UFRJ, Brazil), were grown in DMEM supplemented with $10 \% \mathrm{FBS}$ at $37{ }^{\circ} \mathrm{C}$ in an atmosphere of $5 \% \mathrm{CO}_{2}$, until they reached confluence and then sub-cultivated at least once a week. Prior to the interaction with the yeasts, the HEp2 cells were plated onto 24-well multidishes in the presence of FBS and incubated at $37{ }^{\circ} \mathrm{C}$ for $24 \mathrm{~h}$. After this period, the epithelial cells were washed in Hank's solution and counted in an inverted phase-contrast microscope (Zeiss). For the interaction assay, untreated and lopinavir-treated fungi were added to the monolayer in a ratio of 10:1 (fungi:epithelial cell), and the systems were incubated at $37^{\circ} \mathrm{C}$ in $5 \% \mathrm{CO}_{2}$ for $1 \mathrm{~h}$. Systems were washed with PBS, fixed in Bouin's solution and stained with Giemsa. The percentage of infected epithelial cells was determined by randomly counting at least 200 animal cells in each duplicate through microscopic examination using an immersion objective in a Zeiss Axioplan 2 microscopy. The association index was obtained by multiplying the percentage of infected epithelial cells by the number of fungi per each infected animal cell [46].

\subsection{BALB/c Mice for In Vivo Infections}

Isogenic females of BALB/c mice (6-8 weeks old) were bred at the University of São Paulo (USP; São Paulo, Brazil) in an animal facility under specific pathogen-free conditions, constant temperature, light and dark cycles $12 / 12 \mathrm{~h}$, ad libitum feeding and the supervision of a single person trained and specialized in laboratory animal care. Procedures involving animals and their care were conducted according to the local ethics committee and international rules. All experiments were approved by the Institutional Animal Care and Use Committee of Institute of Biomedical Sciences (ICB) of USP (number 042-127-02). When the survival assay was carried out, rigorous monitoring of infected animals was done twice per day in order to detect any signs of advanced disease, pain or distress. No mice presented some of these symptoms. Some animals died during the night with a rapid evolution of the disease; in this case, the mice were removed early the next day in order to avoid the stress of the other animals, following the guidelines of the Guide for the Care and use of Laboratory animals.

\subsection{Effects of Lopinavir on In Vivo Infection of Immunocompetent Mice}

Six female BALB/c mice per group were intravenously infected with $1 \times 10^{5}$ yeasts of C. albicans. After $1 \mathrm{~h}$ of fungal infection, the animals were treated with PBS (control group), fluconazole (at both 10 and $15 \mathrm{mg} / \mathrm{mL}$ ) and lopinavir (at both 10 and $15 \mathrm{mg} / \mathrm{mL}$ ). The mice survival was evaluated every day during 5 consecutive days, and no animals died during this period. To evaluate the fungal burden, after 5 days post-infection, the animals were anaesthetized with $80 \mathrm{mg} / \mathrm{kg}$ ketamine and $10 \mathrm{mg} / \mathrm{kg}$ of xylazine and then euthanized by cervical dislocation. Subsequently, the kidneys, spleen and liver of the mice were dissected aseptically, weighed and homogenized in $1 \mathrm{~mL}$ of sterile PBS. Aliquots of the homogenate $(100 \mu \mathrm{L})$ were inoculated with a BHI medium containing $2 \%$ agar. After incubation for $24 \mathrm{~h}$ at $37^{\circ} \mathrm{C}$, the number of CFUs was determined. The effectiveness of treatment was 
determined by comparing the number of CFUs per gram of tissue of treated animals with the number of CFUs per gram of tissue of control animals (PBS-treated animals) [47].

\subsection{Effects of Lopinavir on In Vivo Infection of Immunosuppressed Mice}

For immunosuppression of the animals, initially, doses of $100 \mathrm{mg} / \mathrm{kg}$ cyclophosphamide were administered intraperitoneally 4 days and 1 day before infection with $C$. albicans. In addition, 3 days after fungal infection, another dose of cyclophosphamide was applied in order to ensure the animal immunosuppression [48]. The animals were kept in cages lined with wood shavings and closed with autoclaved filter, and served autoclaved food and water in order to maintain a sterile environment. Cages were exchanged twice a week in laminar flow hoods. The animals were considered anergic when the number of leukocytes was found to be less than 100 cells $/ \mathrm{mm}^{3}$ [49]. Six immunosuppressed female BALB/c mice per group were intravenously infected with $1 \times 10^{5}$ yeasts of C. albicans. After $1 \mathrm{~h}$ of fungal infection, the animals were treated with PBS, fluconazole $(10 \mathrm{mg} / \mathrm{mL})$, lopinavir $(10 \mathrm{mg} / \mathrm{mL})$ and a combination of fluconazole and lopinavir (each drug at $10 \mathrm{mg} / \mathrm{mL}$ ). The mice survivability was evaluated every day during 5 consecutive days and, under the employed experimental conditions, some animals died, which allowed the construction of a survival curve. Animals that survive after 5 days post-infection were anaesthetized and then euthanized by cervical dislocation. Then, the kidneys, spleen and liver of the mice were dissected aseptically, weighed, homogenized in $1 \mathrm{~mL}$ of sterile PBS and spread onto BHI agar plates to measure the CFUs. In parallel, the excised kidneys were also fixed in $10 \%$ buffered formalin and dehydrated with increasing concentrations of ethanol. The samples were then treated with xylene and embedded in paraffin. Tissue sections of $3 \mu \mathrm{M}$ were stained with Grocott-Gomori's methenamine silver staining and then examined with an Axio Imager M.2 optical microscope (Zeiss, Jena, Germany).

\subsection{Effects of Lopinavir on the Expression of Sap1-3 Antigens in Post-Mice Passage}

In this set of experiments, the expression of Sap1-3 antigens, which are well-known virulence factors that directly influence the course of infectious process, was compared before and after passage of $C$. albicans in the murine model. To do it, ten yeast colonies isolated from the kidneys of infected mice, which were treated with PBS, fuconazole $(10 \mathrm{mg} / \mathrm{mL})$, lopinavir $(10 \mathrm{mg} / \mathrm{mL})$ and fluconazole + lopinavir (each drug at $10 \mathrm{mg} / \mathrm{mL}$ ) as explained above, were randomly selected from the BHI plate, washed in PBS and grown in the YCB-BSA medium at $37^{\circ} \mathrm{C}$ for $48 \mathrm{~h}$ under agitation (100 rpm). Subsequently, the fungal cells were processed to evaluate the expression of the Sap1-3 antigen by flow cytometry as earlier described in the item 2.11. As a control, C. albicans (strain 11) yeasts only grown in axenic conditions (and never used in in vivo animal infection) were also evaluated to determine the basal level of Sap1-3 expression.

\subsection{Statistics}

All experiments were performed in triplicate, in three independent experimental sets. The results were analyzed statistically by Student's $t$-test (in the comparisons between two groups) and by the Analysis of Variance One-Way ANOVA followed by a Tukey-Kramer post-test (in comparisons between three or more groups). In the case of the survival curve, the Log-rank (Mantel-Cox) test was used to indicate statistical significance. In all analyses, $p$ values of 0.05 or less were considered statistically significant. All analyzes were performed using the program GraphPad Prism version 6.0 (GraphPad Software, San Diego, CA, USA).

\section{Results and Discussion}

\subsection{Lopinavir Binds to Sap2}

It is well-known that $C$. albicans possesses ten distinct Sap genes (Sap1 to Sap10). Saps are classical virulent factors, whose expressions are modulated and/or influenced by the physicochemical environmental conditions, such as $\mathrm{pH}$, temperature, nutrient availability 
and site of infection [50,51]. Sap2 is the best-studied Sap isoenzyme of $C$. albicans; since it is constitutively expressed, it is the dominant Sap isoenzyme in both in vitro and in vivo experimentations; it has broad substrate specificity, and it participates in distinct phases of C. albicans-host interplays [50,51]. Moreover, individuals with candidiasis have high titers of antibodies against Sap2, with soluble antigens present in their serum [52]. Based on those multimodal roles, Sap2 of $C$. albicans is considered a druggable target to new antifungal drugs [53,54]. So, Sap2 was selected to evaluate the ability of lopinavir, a clinically available HIV PI [55], in binding to its catalytic site by an in silico approach.

First of all, a comparison of the docking of the ligand A70450 to Sap2 was taken as a benchmark. The protonation states of Sap2 $\mathrm{D}_{32}$ and a potential quaternary nitrogen atom of the ligand were probed, resulting in four docking runs: protonated ligand and $\mathrm{D}_{32}$, unprotonated $\mathrm{D}_{32}$ and ligand, protonated ligand and unprotonated $\mathrm{D}_{32}$ and unprotonated ligand and protonated $\mathrm{D}_{32}$. The protonated $\mathrm{D}_{32}$ and $\mathrm{A} 70450$ run was the only combination capable of reproducing the experimental geometry of the complexed ligand to Sap2 (Figure S2). The protonation of the nitrogen atom in the ring of A70450 is necessary due to the vicinity of the side chain carboxylate group of $\mathrm{D}_{120}$ to the ring (Figure S2). This effect is therefore expected to play a minor role in the smaller ligand lopinavir.

Taken together, the estimated $\mathrm{pKa}$ of $\mathrm{D}_{32}$ and the above results, this residue was considered in its protonated form for the dockings with lopinavir. The docking results are summarized in Table 1, where the relative binding free energies for the geometries where the ligands interact with $\mathrm{D}_{32}, \mathrm{D}_{218}$ and $\mathrm{G}_{85}$ are listed along with their ranked position. Cluster rank 1 means the best binding mode, while 9 represents the worst binding mode, within an estimated $3 \mathrm{kcal} / \mathrm{mol}$ maximum difference. In fact, the protonation state of the nitrogen atom of the ring in lopinavir did not seem to be energetically decisive in binding Sap2. However, taking into account the most prevalent conformation and the energetic criterion, it suggested that lopinavir binds preferentially in its unprotonated form (Table 1). This finding seems consistent with the absence of negatively charged residues in the vicinity of this ring in lopinavir. Its docked geometry reveals a very similar binding mode to A70450 (Figure 1A,B). All residues interacting with lopinavir do also interact with A70450 $\left(\mathrm{G}_{85}, \mathrm{D}_{32}, \mathrm{D}_{218}, \mathrm{G}_{220}\right.$ and $\left.\mathrm{T}_{222}\right)$ (Figure $\left.1 \mathrm{~A}\right)$. In addition, both ligands bind to C. albicans Sap2 with very similar binding free energies (difference is within the method uncertainty).

Table 1. Molecular docking binding free energies and associated ranking to the different ligands when interacting with $C$. albicans Sap2 catalytic site $\left(\mathrm{D}_{32}, \mathrm{D}_{218}\right.$ and $\left.\mathrm{G}_{85}\right)$.

\begin{tabular}{ccc}
\hline Ligands & Estimated Binding Free Energy (kcal/mol) & Cluster Ranking \\
\hline A70450 (standard inhibitor, protonated form) & -9.5 & 1 \\
\hline Lopinavir (unprotonated) & -9.0 & 1 \\
\hline Lopinavir (protonated) & -8.6 & 3 \\
\hline
\end{tabular}

Molecular docking methods provide an approach to the ranking of potential ligands with respect to their ability to interact with a given target [56]. It involves efficient sampling of possible poses of the small molecules in the specified binding pocket of a protein in order to identify the optimal binding geometry, as measured by a score function [57]. The results presented herein revealed for the first time the ability of the HIV PI lopinavir to bind to the catalytic site of Sap2 produced by C. albicans. A simple explanation for this result is based on the fact that both HIV-1 protease and Sap2 belong to the same superfamily of aspartic proteases. In addition, the tridimensional structure superimposition of Sap2 and HIV-1 protease confirmed the similarity between their active sites and flap regions [58]. However, while many chemical interactions are common to the bind of lopinavir to both viral and fungal aspartic proteases, the different electrostatic and hydrophobic contributions in each active site will lead to distinct inhibitory potential. In this sense, distinct HIV PIs have similar Ki against HIV-1 protease at the nanomolar range, while the affinity for Sap2 of $C$. albicans is much lower usually at the micromolar range [53,59]. 


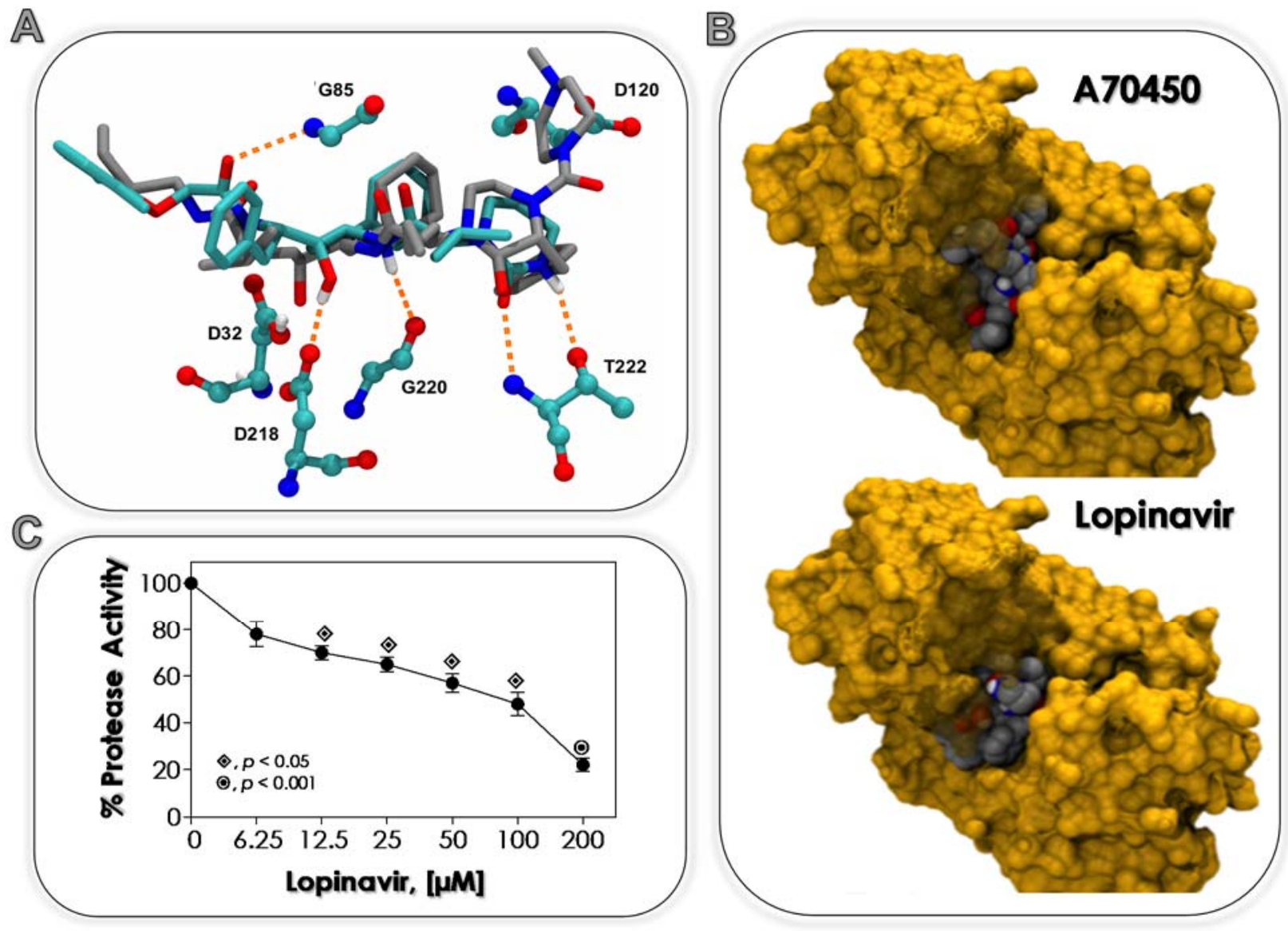

Figure 1. (A) Comparison of the geometries of the docked A70450 to C. albicans Sap2 catalytic site as determined experimentally (carbon atoms in gray) and the best binding mode for lopinavir (unprotonated form) by molecular docking (carbon atoms in cyan). Potential hydrogen bonds are shown by orange dashed lines. Remaining atoms are color-coded as oxygen: red, nitrogen: blue, hydrogen: white. Except for the polar hydrogen of $\mathrm{D}_{32}$, the remaining protein hydrogen atoms were removed for clarity. (B) Molecular docking of A70540 and lopinavir. The protein is represented by its molecular surface in yellow and the ligands in CPK model (atoms are color-coded as carbon: gray, oxygen: red, nitrogen: blue; hydrogen: white). (C) Effects of lopinavir on the Sap activity detected in conditioned supernatant of C. albicans. Fungal supernatant was incubated in the absence and in the presence of different concentrations of lopinavir, and then the proteolytic activity was measured spectrophotometrically using BSA as protein substrate. The values represent the mean \pm standard deviation of three independent experiments performed in triplicate. The symbols highlight the statistically significant differences (Student's t-test) between untreated and lopinavir-treated systems.

A detailed work published by Calugi et al. [58] described that both ritonavir and saquinavir, two first-generation HIV PIs, were able to interact with both catalytic $\mathrm{D}_{218}$ and $\mathrm{D}_{32}$, as observed in the HIV-1 protease complex, and another hydrogen-bond is established between the main chain carbonyl moiety and $\mathrm{G}_{85}$ amide proton. That result is similar to which was observed herein with lopinavir, a second-generation HIV PI. Additionally, docking results showed that saquinavir addressed S2/S2' and S1/S1' Sap2 binding pockets, while ritonavir [58] and lopinavir (present work) addressed the S3 subsite of the Sap2 active site. Based on the structure of Sap2 of $C$. albicans complexed with the standard inhibitor A70450, it has been proposed that binding to the S3 region is critical for the efficient inhibition of this enzyme [60]. Interestingly, ritonavir also bound to the Sapp1p active site of Candida parapsilosis in an extended conformation and occupied the S2-S3' enzyme substrate binding subsites, and the hydroxyl group of the central ritonavir moiety formed two hydrogen bonds with the side-chains of the two catalytic aspartates $D_{32}$ and $\mathrm{D}_{220}[61]$. 


\subsection{Lopinavir Inhibits Sap Activity}

It is well-known that $C$. albicans cells are able to secret Saps to the extracellular environment when grown in a chemically defined medium supplemented with a single protein source, such as albumin and hemoglobin [26]. Corroborating this statement, it was showed that C. albicans strain 11 (which was used in all parts of the present study) secreted aspartic-type proteases, particularly Sap2, as judged by the ability to degrade soluble BSA, the inhibition of the proteolysis by pepstatin A (a prototypal inhibitor of Saps) and the recognition by the anti-Sap antibody (Figure S1) [33]. As experienced in the present work, lopinavir was able to inhibit the BSA degradation in a typically concentration-dependent manner (Figure $1 \mathrm{C}$ ), showing an $\mathrm{IC}_{50}$ of $58.7 \mu \mathrm{M}$.

As is well documented in the current literature, HIV PIs have been described as potential inhibitors of Sap produced by clinically relevant fungi. For example, amprenavir blocked C. albicans Sap activity, whose inhibition increased from $85 \%$ to $100 \%$ as drug concentration increased from 6.25 to $200 \mu \mathrm{M}$ [33]. Indinavir at $1 \mu \mathrm{M}$ reduced the C. albicans Sap activity by more than $50 \%$, increasing the inhibitor concentration to $10 \mu \mathrm{M}$, completely abolishing the proteolysis [62]. Indinavir also restrained the aspartic protease secreted by Cryptococcus neoformans yeasts [63]. Valle et al. [64] showed that seven out of nine HIV PIs significantly reduced the hydrolytic activity of Sap-like enzymes produced by Trichosporon asahii, presenting inhibition profiles ranging from 52 to 67\% (atazanavir > nelfinavir $=$ ritonavir $=$ lopinavir $>$ indinavir $=$ amprenavir $>$ saquinavir , while tipranavir and darunavir did not inhibit the proteolysis. Mycelial [65], conidial [34] and sclerotic [66] cells of the filamentous fungus Fonsecaea pedrosoi were able to produce Saps when grown under chemically defined conditions, which were inhibited at different proportions to indinavir, saquinavir, ritonavir and nelfinavir. Phialophora verrucosa mycelial cells also extracellularly released aspartic-type protease, which was inhibited by HIV PIs at $100 \mu \mathrm{M}$ as follows: amprenavir $(\sim 77 \%)$, ritonavir $(\sim 76 \%)$, lopinavir $(\sim 75 \%)$, indinavir $(\sim 51 \%)$, atazanavir $(\sim 46 \%)$, saquinavir $(\sim 41 \%)$ and nelfinavir $(\sim 36 \%)$ [67]. Collectively, all these results confirm that aspartic proteases produced by opportunistic human fungal pathogens are genuine targets of the HIV PIs.

\subsection{Lopinavir Interferes with Growth Behavior, Morphometrical Parameters and Morphology}

Antimicrobial action is directly dependent on two main parameters: inoculum size and drug concentration. Moreover, inoculum concentration (in other words, the number of available targets) may particularly affect antifungal drugs whose antimicrobial activity is based on an enzymatic mechanism $[68,69]$. In this context, we analyzed the effects of lopinavir using distinct fungal densities and different concentrations of this drug. Lopinavir at $50 \mu \mathrm{M}$ was able to affect the viability of $C$. albicans considerably in densities ranged from $10^{2}$ to $10^{4}$ yeasts; while using both $10^{5}$ and $10^{6}$ yeasts, the growth behavior was not statistically different in comparison with untreated fungi (Figure 2A). In addition, $10^{6}$ yeasts treated for $20 \mathrm{~h}$ with a higher lopinavir concentration $(200 \mu \mathrm{M})$ had no alterations in CFU counts compared to the control cells (Figure $2 \mathrm{~B}$ ). On the other hand, when $10^{3}$ yeasts were incubated with lopinavir, a typically dose-dependent inhibition on the growth rate was clearly observed (Figure $2 \mathrm{C}$ ), displaying an $\mathrm{IC}_{50}$ of $39.8 \mu \mathrm{M}$.

Lopinavir induced alterations in fungal morphometrical parameters, causing a significant reduction in cellular size and granularity (Figure 2D). A simple inspection of C. albicans cells treated with lopinavir by means of light and fluorescence microscopies revealed some morphological alterations, including non-rounded, petite and lysed cells, compared to the typical appearance of rounded-shape yeasts (Figure 3). Interestingly, lopinavir also induced the appearance of small hyphae in the culture (Figure 3).

Amprenavir was also able to inhibit the growth of C. albicans in typically concentrationand number of yeast (target)-dependent ways, but displaying an $\mathrm{IC}_{50}$ value three times higher compared to lopinavir [33]. In addition, amprenavir at $100 \mu \mathrm{M}$ promoted a reduction of $30 \%$ in C. albicans' size compared with untreated cells [33]. Ritonavir at $8 \mathrm{mg} / \mathrm{mL}$ interfered with the consumption of albumin by $C$. albicans and C. parapsilosis when cultured 
in YCB-BSA medium, reducing the growth rate in 50\% after 23 and $86 \mathrm{~h}$, respectively, probably by blocking the access to the nitrogen source as previously proposed as the main inhibitory mechanism [26]. This proposal is exactly as expected from the commonly agreed-upon model of the positive feedback mechanism of Sap gene expression, which is up-regulated by peptides generated by the initial albumin proteolysis by the constitutively expressed Saps [70,71].

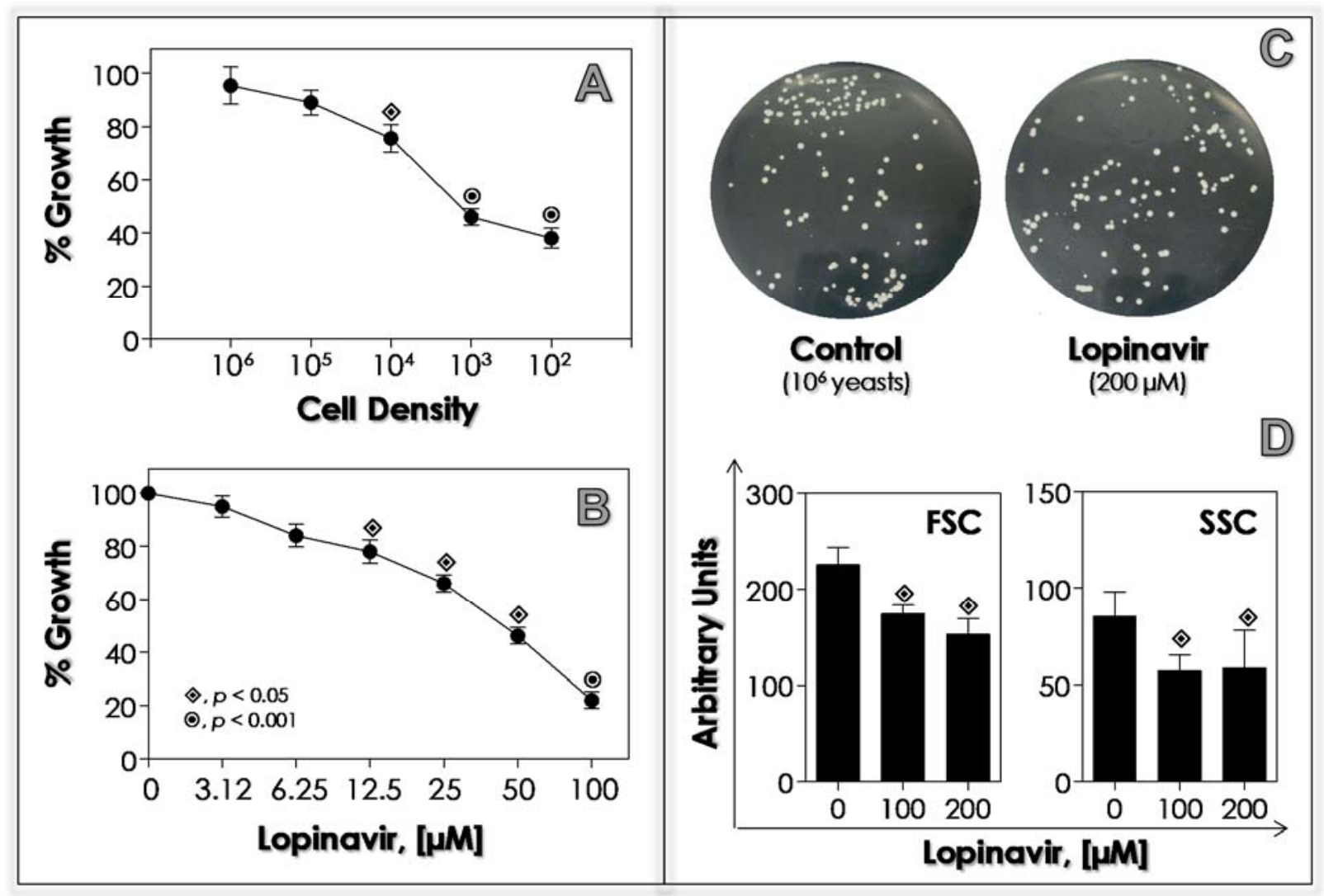

Figure 2. Effects of lopinavir on the growth of C. albicans yeast cells. (A) Different fungal densities $\left(10^{2}-10^{6}\right.$ yeasts) were treated with lopinavir at $50 \mu \mathrm{M}$. (B) Yeasts $\left(10^{3}\right.$ cells) were treated with different concentrations of lopinavir $(0-100 \mu \mathrm{M})$. In both set of experiments, the yeasts were incubated for $20 \mathrm{~h}$ at $37^{\circ} \mathrm{C}$ with slight agitation. A control was made replacing lopinavir with PBS, which was considered as $100 \%$ of growth. Inhibition ratio was determined by CFU measurements. (C) The representative plates demonstrate the treatment of high cellular density ( $10^{6}$ yeasts) with lopinavir at $200 \mu \mathrm{M}$ for $20 \mathrm{~h}$, revealing a similar growth rate in comparison to the untreated ones. (D) In parallel, $10^{6}$ yeasts were treated (or not) with lopinavir (at both 100 and $200 \mu \mathrm{M}$ ) for $20 \mathrm{~h}$ and then analyzed by flow cytometry in order to measure size and granularity. Forward scatter (FSC) measurement is related to cell size, and side scatter (SSC) measurement is related to the internal granularity and/or complexity of a cell. In all cases, the values represent the mean \pm standard deviation of three independent experiments performed in triplicate. The symbols indicate the experimental systems considered statistically significant from the control (Student's $t$-test).

Nonetheless, contrasting results have been published regarding the ability of HIV PIs to act as antifungal drugs. In this context, indinavir did not affect the C. albicans viability at concentrations up to $1 \mathrm{mg} / \mathrm{mL}$, while saquinavir $(1 \mathrm{mg} / \mathrm{mL})$ was even fungicidal as assessed by three different viability assays (CFU, MTT, propidium iodide staining), and ritonavir at the same concentration significantly affected the mitochondrial activity only [62]. Indinavir, a HIV PI capable of crossing the blood-brain barrier, was vastly tested against $C$. neoformans, since this fungus has a tropism to the brain. Indinavir impaired the C. neoformans' growth in typically time- and dose-dependent fashions for both reference strains and clinical isolates as judged by the CFU assay [63]. However, mitochondrial viability (assessed by either MTT or JC-1) and plasma membrane integrity (propidium 
iodide staining) were not affected after exposure of $C$. neoformans to indinavir at $10 \mu \mathrm{M}$ [63]. Mata-Essayag et al. [72] reported that all 73 clinical isolates of $C$. albicans were susceptible to saquinavir, while 23 were susceptible to indinavir, 12 to ritonavir and 3 to nelfinavir. Notably, C. albicans clinical isolates $(n=17)$ resistant to fluconazole were also susceptible to saquinavir [72].

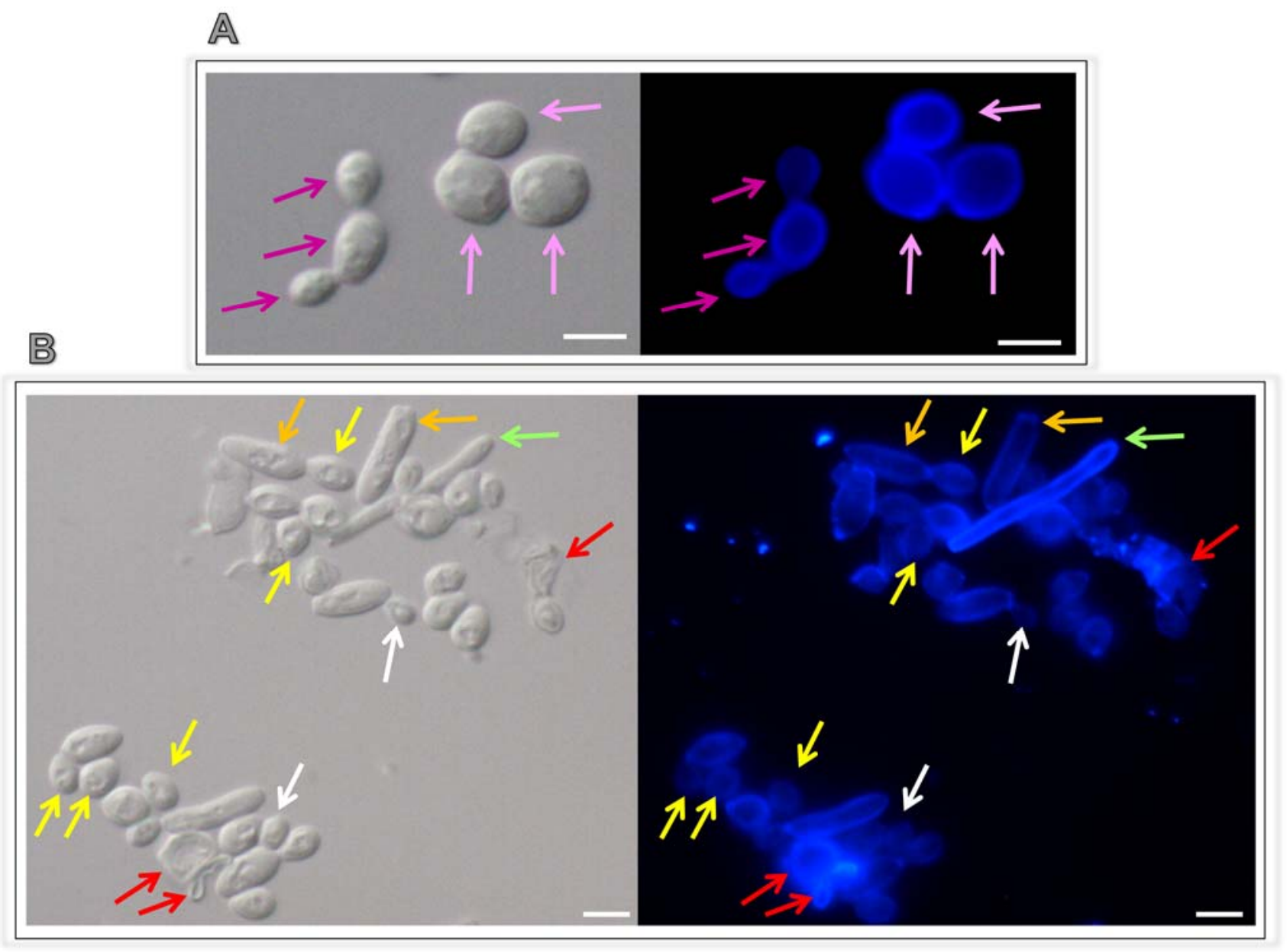

Figure 3. Light and fluorescent microscopy images exemplifying the morphological differences observed in $C$. albicans cells grown in YCB-BSA medium in the absence (A) and in the presence of $200 \mu \mathrm{M}$ lopinavir (B) for $20 \mathrm{~h}$. The control cell population is homogeneous and consists of rounded yeast cells (light pink arrows) and pseudohyphae (dark pink arrows). Contrarily, the treatment with lopinavir induces some clear morphological alterations, including petite cells (white arrows), smaller and ovoid cells (yellow arrows), large non-ovoid cells (orange arrows) and ghost or lysed cells (red arrows), as well as some small hyphae (green arrow) were observed. Bars $=5 \mu \mathrm{M}$.

Ritonavir was able to reduce the in vitro growth of planktonic cells of Trichosporon asahii and Trichosporon inkin up to $25 \mu \mathrm{g} / \mathrm{mL}$, causing a reduction of $\sim 100 \%$ at $200 \mu \mathrm{g} / \mathrm{mL}$ [73]. Both saquinavir and ritonavir powerfully inhibited the growth of clinical isolates of the dimorphic fungus Histoplasma capsulatum, presenting MIC values ranging from 0.125 to $1 \mu \mathrm{g} / \mathrm{mL}$ for saquinavir considering both filamentous and yeast phases as well as MICs from 0.0312 to $4 \mu \mathrm{g} / \mathrm{mL}$ and 0.0625 to $1 \mu \mathrm{g} / \mathrm{mL}$ for ritonavir against filamentous and yeast phases, respectively [74]. Additionally, those authors reported the synergistic interactions among the combinations of itraconazole with saquinavir or ritonavir against $H$. capsulatum, culminating with a significant reduction in the MIC values of these drugs [74]. The growth of $F$. pedrosoi conidial and sclerotic cells was affected by the treatment with HIV PIs (nelfinavir, ritonavir, saquinavir and indinavir), in which indinavir and ritonavir (both at $100 \mu \mathrm{M})$ were the best PIs to block conidial viability and saquinavir $(100 \mu \mathrm{M})$ the only one 
able to reduce the viability of sclerotic cells $[34,41,65]$. In parallel, a significant reduction in the cellular granularity was seen in HIV PIs-treated F. pedrosoi conidia, but no alteration was observed in the size parameter [41]. Ritonavir was capable of promoting significant growth inhibition of $P$. verrucosa, with a significant decrease of 60,45 and $40 \%$ at 400,200 and $100 \mu \mathrm{M}$, respectively, displaying an $\mathrm{IC}_{50}$ of $141.42 \mu \mathrm{M}$ [67].

\subsection{Lopinavir Alters Ultrastructural Architecture}

TEM visualization revealed that untreated C. albicans yeast cells had a normal morphology with a typical dark and dense cytoplasm, well-delineated plasma membrane and distinct cell wall structure with preserved external fibrils (Figure 4A). Lopinavir promoted significant changes in the surface topography, including (i) augmentation in cell wall thickness (Figure 4B); (ii) reduction (treatment with lopinavir at $100 \mu \mathrm{M}$ ) and total loss (treatment with lopinavir at $200 \mu \mathrm{M}$ ) of the fibrils composing the outermost part of the cell wall (light and dark green arrows, respectively) (Figure 4C,E). Additionally, disorder and detachment of cell wall (Figure 4D), empty cytoplasm resembling ghost cells, plasma membrane presenting numerous undulations and/or invaginations and withdrawal of the plasma membrane from the cell wall were observed in lopinavir-treated fungi (Figure 4E). Taken together, all these significant alterations corroborate the anti-proliferative properties of lopinavir upon C. albicans.

SEM assay was conducted to better reveal the surface modifications provoked by lopinavir treatment in C. albicans. As expected, spherical to oval yeasts containing several protrusions (rough surface) were observed in non-treated cells (Figure 5, control). Lopinavir-treated cells presented a smooth surface, some cells presenting a clear detachment of the outside cover (the fibrils) and others containing a focus of attached material, which might represent remnants of the former surface's irregular external layer (Figure 5, yellow arrows). In addition, lopinavir induced considerable changes in the shape (e.g., yeasts lose their typical oval/round shape) and in the surface sculpturing (e.g., invaginations forming cavitations were usually seen in the surface of both yeasts and daughter cells) (Figure 4, white arrows). Disrupted (lysed) cells, showing only the remaining framework, were also observed, particularly when fungal cells were treated with lopinavir at $200 \mu \mathrm{M}$ (Figure 5, white circle and blue star). Filamentation was detected in some lopinavir-treated cells; however, this structure presented serious surface injuries such as those described in yeasts (Figure 5, white brackets).

Similar ultrastructural alterations were observed in amprenavir-treated C. albicans cells by means of SEM analysis, particularly the conversion of the rough surface in untreated yeasts to the smooth one after the drug treatment [33]. In fact, different HIV PIs promoted analogous ultrastructural alterations in distinct fungi independent of the morphological stage. In this context, treatment with nelfinavir or saquinavir (both at $100 \mu \mathrm{M}$ ) induced several ultrastructural changes in crucial structures/organelles of F. pedrosoi conidial cells as visualized by TEM, including: invaginations in the plasma membrane and detachment of the plasma membrane from within the cell wall, disorder and detachment of the cell wall, breakage of cell wall starting from the extracellular environment, shedding of a great amount of electron-dense and amorphous material on the outer side of the cell wall, rupture of internal organelles and presence of large and irregular cytoplasmic vacuoles, some of them containing small vesicles and others so intense that they occupied almost the entire cytoplasm $[34,41]$. 

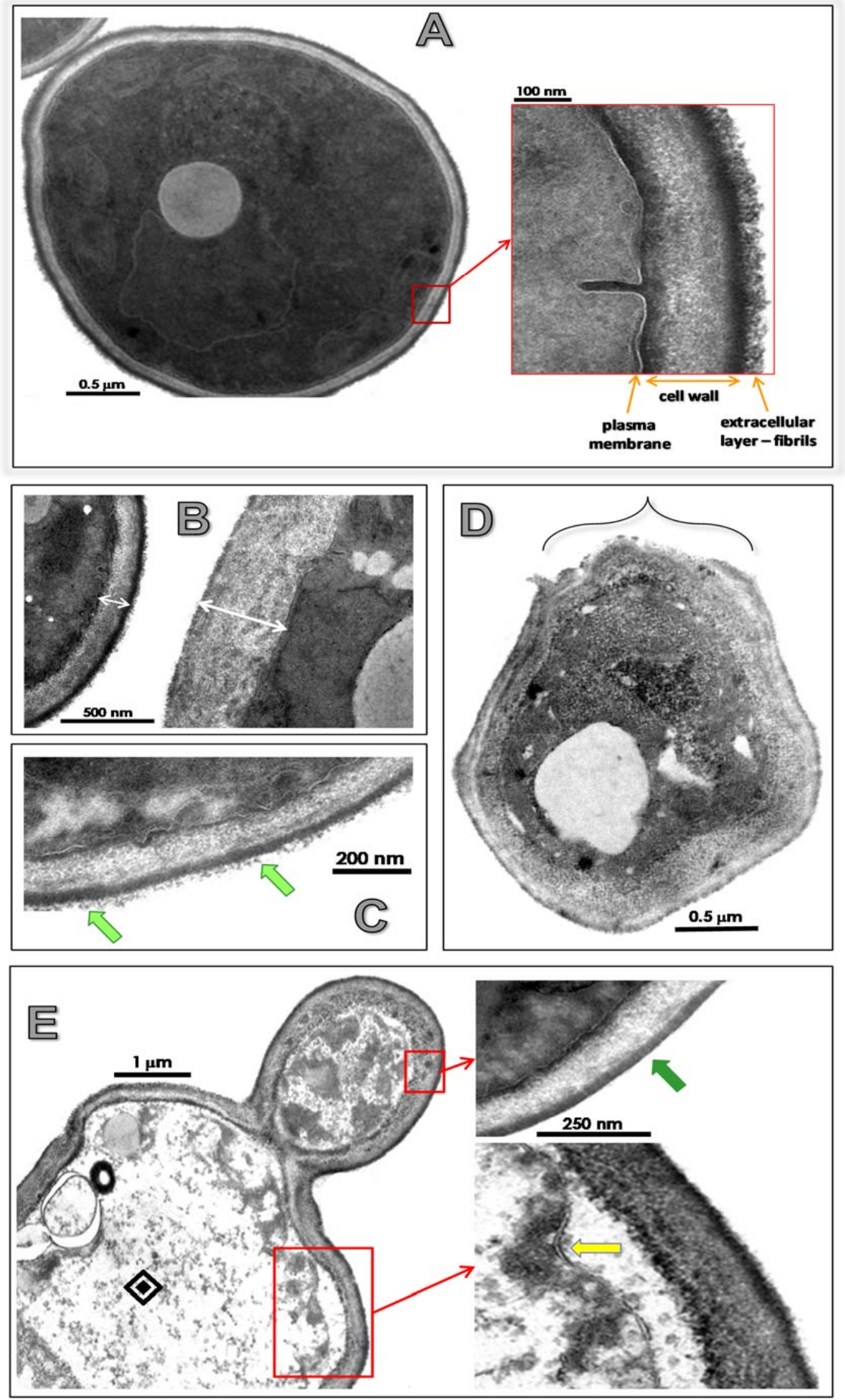

Figure 4. Effects of lopinavir on the ultrastructure of C. albicans yeast cells. (A) Untreated and (B-E) lopinavir (100 and $200 \mu \mathrm{M}$ )-treated fungal cells were processed and analyzed by transmission electron microscopy. (A) Control yeasts present 
a dense cytoplasm with a well-delineated plasma membrane and a compact cell wall, in which the external fibril layer is clearly evidenced (for better visualization, see the amplification of the selected surface area). (B) Some lopinavir-treated cells presented a significant augmentation in the cell wall thickness compared to untreated ones (compare the cell wall thickness of the control cell at the left with the lopinavir-treated cell at the right; the cell walls were delimited by white arrows to facilitate the comparison). (C,E) The external fibril layer is rarefied by the treatment with lopinavir at $100 \mu \mathrm{M}$ (C-green arrows) and totally lost by lopinavir at $200 \mu \mathrm{M}$ (E-green arrows). (D) The symbol appoints the breakage of cell wall starting from extracellular medium. (E) The yellow arrow indicates the invagination of the plasma membrane with consequent withdrawal from the cell wall following treatment of yeasts with lopinavir at $200 \mu \mathrm{M}$.
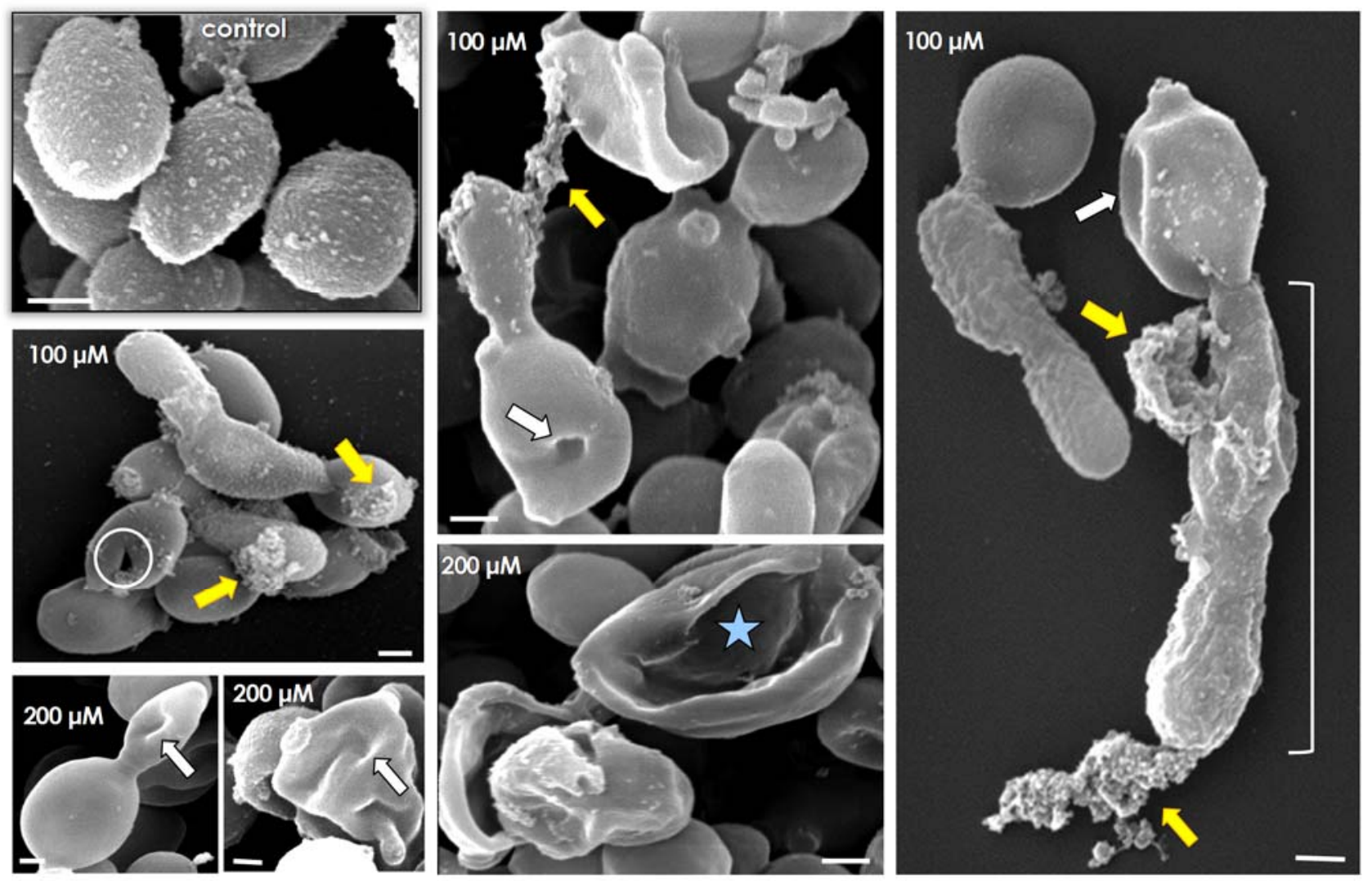

Figure 5. Effects of lopinavir on the ultrastructure of C. albicans cells. Untreated and lopinavir (100 and $200 \mu \mathrm{M})$-treated fungal cells were processed and analyzed by scanning electron microscopy. Control cells are characterized by oval-to-round cells with a rough surface, covered by several protrusions. The treatment with lopinavir promoted (i) the detachment of surface materials from the cell wall in both yeasts and filamentous (delimited by brackets) as indicated by yellow arrows; (ii) the conversion of rough surface to smooth one; (iii) surface invaginations in both yeast and daughter cells (white arrows); (iv) alterations on yeast shape, some of them with altered surface sculpturing and (v) lysis of fungal cells (white circle and blue star). Bars $=0.5 \mu \mathrm{M}$.

\subsection{Lopinavir Arrests the Yeasts-into-Hyphae Transformation}

The fascinating ability of fungi to switch between different morphological states is associated with their adaptability, plasticity and pathogenicity. For instance, hyphal growth is able to exert a mechanical force and to secrete a plethora of hydrolytic enzymes, which facilitates the fungal penetration and dissemination inside the host cells and tissues as well as helps to escape from phagocytosis $[75,76]$. The morphogenesis is a hallmark of the virulence and successfully infectious process of C. albicans $[77,78]$. So, drugs able to arrest the morphogenesis process can be considered promising antifungals. In this context, SEM analysis revealed that lopinavir was capable of causing drastic ultrastructural alterations in both C. albicans yeast and filamentous forms (Figure 5). Herein, the effects of lopinavir on yeast into germ tube differentiation (filamentation process) were evaluated using a 
cellular density ( $10^{6}$ yeasts) in which lopinavir was not able to interfere with the fungal viability (Figure 2). The results evidenced that lopinavir arrested the yeast into the germ tube transformation in a concentration-dependent manner (Figure 6).

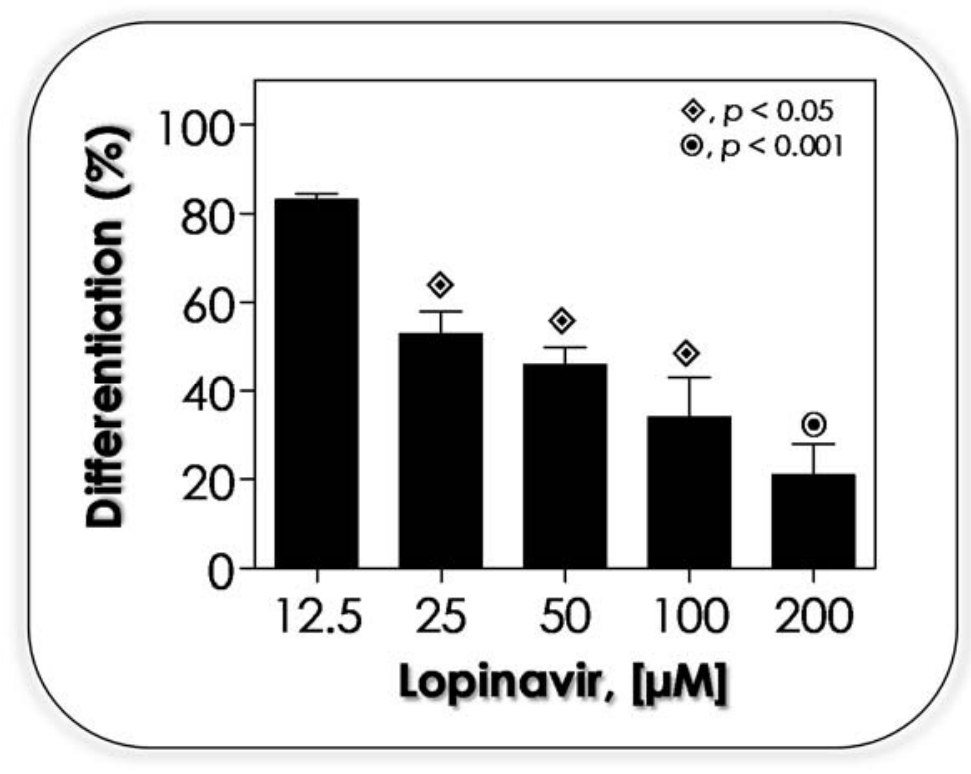

Figure 6. Effect of lopinavir on C. albicans yeast into germ tube transformation (morphogenesis process). Germination was performed by incubating the yeasts $\left(10^{6}\right.$ cells) in fetal bovine serum for $4 \mathrm{~h}$ at $37^{\circ} \mathrm{C}$ in the absence or in the presence of lopinavir at different concentrations. The number of cells presenting germ tube formation was counted in a Neubauer chamber. The values represent the mean \pm standard deviation of three independent experiments performed in triplicate. The symbols indicate the experimental systems considered statistically significant from the control (Student's $t$-test).

Gruber et al. [62] described that indinavir did not arrest the ability of C. albicans yeasts to form hyphae; however, hyphal elongation of drug-treated cells was delayed by approximately $45 \%$ after incubation with indinavir at $0.5 \mathrm{mg} / \mathrm{mL}$. Amprenavir blocked the yeast into the germ tube transformation in C. albicans in a typically concentration-dependent way, in which $100 \mu \mathrm{M}$ of the drug was able to arrest the process by approximately $50 \%$ [21]. Saquinavir drastically blocked the F. pedrosoi conidia into mycelia transformation observed during the in vitro interaction with epithelial cells [34]. Contrarily, incubation of C. albicans with $0.01 \mu \mathrm{g} / \mathrm{mL}$ tipranavir, which is the only non-peptidic HIV PI, favored the in vitro mycelial transition [79].

\subsection{Lopinavir Disturbs the Synthesis of Neutral Lipids}

A common side effect described in individuals who need to use HIV PIs is the interference on the lipid metabolism [80,81]. With this task in mind, we evaluate the effects of lopinavir in the lipid metabolism in C. albicans, focusing on the neutral lipids due to their relevance in several crucial processes to yeast cells. These lipids are located in intracellular storages (called lipid bodies) and in plasma membrane (ergosterol) [82]. Our results showed that neutral lipids inside the lipid bodies were drastically reduced by the treatment of yeasts with lopinavir, in a classically dose-dependent way, as judged by both fluorescent microscopy and flow cytometry assays using the fluorophore Nile red (Figure 7A,B, respectively). In consonance, the production of ergosterol was also drastically diminished as revealed by HTPLC assay (Figure 7C). Together, these results can justify the detachment of plasma membrane from the cell wall observed in lopinavir-treated $C$. albicans cells by TEM images, since sterol regulates the plasma membrane fluidity. 

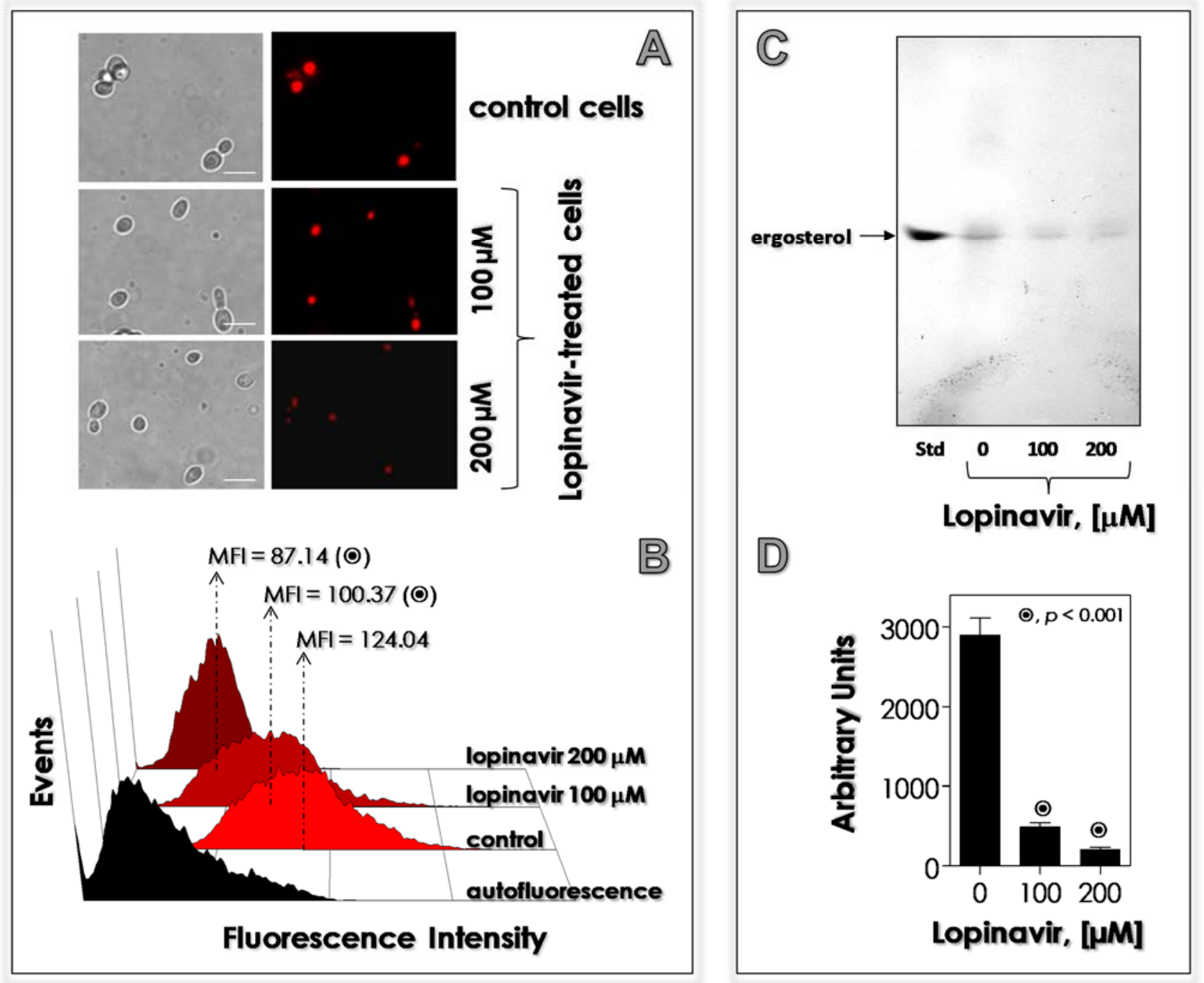

Figure 7. Effect of lopinavir on the production of neutral lipids in C. albicans. In this set of experiments, yeast cells were incubated for $20 \mathrm{~h}$ in the absence ( 0 or control cells) and in the presence of lopinavir at both 100 and $200 \mu \mathrm{M}$. After that, yeasts were analyzed to detect neutral lipid inclusions (A,B) and ergosterol (C,D). (A) Differential interference contrast microscopy (left images) and fluorescence microscopy with Nile red (right images) evidenced the intracellular lipid inclusions. (B) Flow cytometry assay corroborated the fluorescence microscopy, which showed a drastic reduction in Nile red-positive cells as judged by the drop in the mean of fluorescence intensity (MFI). (C) High-performance thin-layer chromatography (HPTLC) showing the ergosterol chemically extracted from the yeast cells as well as the ergosterol standard (Std), which was applied into the same plate. (D) Densitometrical analyses of the ergosterol-corresponding bands, expressed in arbitrary units, were shown. The symbols indicate the experimental systems considered statistically significant from the control (Student's $t$-test).

Few studies reported the effect of HIV PIs on the lipid metabolism in fungi. Regarding sterol content, untreated conidia of $F$. pedrosoi showed an equal proportion of lanosterol (a precursor of the ergosterol biosynthesis pathway) and ergosterol (the final product) [41]. Contrarily, no ergosterol was detected in nelfinavir-, indinavir-, ritonavir- and saquinavirtreated F. pedrosoi conidial cells, whereas lanosterol production was inhibited by saquinavir, ritonavir $(\sim 60 \%)$ and nelfinavir $(\sim 40 \%)$, but not by indinavir [41]. The treatment of $C$. albicans cells with amprenavir at $200 \mu \mathrm{M}$ hugely reduced (90\%) the amount of plasma membrane-located ergosterol [33]. 


\subsection{Lopinavir Modulates the Surface-Located Molecules}

SEM images clearly revealed a detachment of external fibrils from the surface of lopinavir-treated C. albicans cells, which is a place rich in glycomolecules and enzymes (Figure 5), that suggests a perturbation in this vital structure directly involved in the interaction (e.g., adhesion events) with the environment [83]. Mannose-containing glycoconjugates (e.g., mannoproteins) were detected in the surface of both untreated and lopinavir-treated yeasts in similar proportions $(\% \mathrm{FC})$; however, lopinavir induced a significant reduction in the amount of these glycomolecules as observed by the drop in the MFI parameter ( 20 and $70 \%$ after treatment with 100 and $200 \mu \mathrm{M}$ of lopinavir, respectively) in the ConA-labeled cells (Table 2). A similar profile was detected when the yeast cells were incubated with the anti-Sap1-3 antibody, revealing a decrease in the Saps located at the surface of lopinavir-treated cells (Table 2). Sialic acid-containing glycoconjugates were negatively altered considering both \%FC and MFI parameters due to the treatment with lopinavir (Table 2). Contrarily, lopinavir promoted a substantial increase in the production of $\mathrm{N}$-acetylgucosamine-rich molecules in C. albicans (Table 2).

Table 2. Effects of lopinavir on the expression of cell surface molecules in C. albicans.

\begin{tabular}{|c|c|c|c|c|c|c|c|c|}
\hline \multirow[t]{2}{*}{ [Lopinavir] } & \multicolumn{2}{|c|}{$\begin{array}{c}\text { Sialic Acid-Rich } \\
\text { Molecules } \\
(\text { LFA-Labeled Cells })^{a}\end{array}$} & \multicolumn{2}{|c|}{$\begin{array}{c}\text { Mannose-Rich } \\
\text { Molecules } \\
\left(_{\text {ConA-Labeled Cells })^{a}}\right.\end{array}$} & \multicolumn{2}{|c|}{$\begin{array}{c}\text { N-Acetylglucosamine-Rich } \\
\text { Molecules } \\
{(W G A-L a b e l e d ~ C e l l s)^{a}}^{\text {a }}\end{array}$} & \multicolumn{2}{|c|}{$\begin{array}{c}\text { Surface-Located } \\
\text { Aspartic Proteases } \\
\text { (Sap1-3-Labeled Cells) }^{a}\end{array}$} \\
\hline & $\% \mathrm{FC}^{\mathrm{b}}$ & $\mathrm{MFI}^{\mathrm{b}}$ & $\% \mathrm{FC}$ & MFI & $\% \mathrm{FC}$ & MFI & $\% F C$ & MFI \\
\hline None & $41.96 \pm 3.2$ & 542.68 & $99.22 \pm 0.4$ & 1858.30 & $48.35 \pm 1.3$ & 114.62 & $88.77 \pm 0.3$ & 753.58 \\
\hline $100 \mu \mathrm{M}$ & $30.75 \pm 1.3^{*}$ & $300.57^{* *}$ & $94.86 \pm 3.3$ & 1502.74 * & $59.72 \pm 0.9 *$ & 161.03 ** & $90.01 \pm 1.7$ & 620.88 * \\
\hline $200 \mu \mathrm{M}$ & $25.30 \pm 0.5^{* *}$ & $236.97 * *$ & $92.62 \pm 2.9$ & $598.31 * *$ & $74.04 \pm 2.0 * *$ & $198.52 * *$ & $89.39 \pm 1.1$ & $366.67 * *$ \\
\hline
\end{tabular}

a \%LFA, Limax flavus agglutinin; ConA, Concanavalin A lectin; WGA, wheat germ agglutinin; Sap1-3; antibody against Sap1-3 of C. albicans.

$\mathrm{b} \% \mathrm{FC}$, percentage of fluorescent-labeled cells; MFI, mean of fluorescence intensity. ${ }^{*}, p<0.05 ;{ }^{* *}, p<0.001$.

Indinavir showed a dose-dependent decrease in cell-bound Sap2 in C. albicans as judged by flow cytometry using an anti-Sap 2 monoclonal antibody, for instance, reducing around $30 \%$ when yeasts were grown in the presence of indinavir at $0.05 \mathrm{mg} / \mathrm{mL}$ [62] Amprenavir (at both 100 and $200 \mu \mathrm{M}$ ) also reduced the expression of surface molecules in C. albicans, including Sap antigens and mannose- and sialic acid-rich glycoconjugates [33]. The pre-exposure of T. asahii and T. inkin cells to ritonavir at $100 \mu \mathrm{g} / \mathrm{mL}$ for 14 days reduced the cell surface hydrophobicity, which is considered a predictor for adhesion and biofilm formation. Flow cytometry analyses demonstrated that indinavir, saquinavir, ritonavir and nelfinavir significantly diminished the percentage of fluorescently ConAlabeled F. pedrosoi conidial cells by approximately $54,32,22$ and $20 \%$, respectively, when compared to untreated conidia, as well as dropped the MFI values, which indicated a reduction in the surface amount of mannose-rich glycoconjugates. In contrast, the sialic acid expression was not significantly altered in F. pedrosoi by the treatment with the HIV PIs. Interestingly, indinavir and ritonavir diminished the production of surface melanin in F. pedrosoi conidia, which led to the exposition of internal (which were hidden) molecules such as glucosylceramide [41]. These data highlight the anti-virulence properties of HIV PIs. Efficient antifungal drugs need to be capable of blocking at least some of their virulence markers.

\subsection{Lopinavir Diminishes the Secretion of Hydrolytic Enzymes}

The secretion of molecules by fungal cells is a process dependent on the plasma membrane and cell-wall integrity [84]. Moreover, fungal viability depends on the secretion of hydrolytic enzymes to degrade extracellular macromolecules and to interact with abiotic/biotic structures present in the environment [85]. In addition to secreting aspartic proteases as earlier reported, C. albicans strain 11 was also able to secrete esterase, but not phospholipase, under the herein employed experimental conditions. Lopinavir treatment 
significantly diminished the secretion of both aspartic protease and esterase activities (Table 3).

Table 3. Effects of lopinavir on the production of extracellular hydrolytic enzymes by C. albicans.

\begin{tabular}{ccc}
\hline Lopinavir & Esterase Activity $(\boldsymbol{P z} \text { Value })^{\text {a }}$ & $\begin{array}{c}\text { Aspartic Protease Activity } \\
(\boldsymbol{P z} \text { Value })\end{array}$ \\
\hline None & $0.576 \pm 0.011$ & $0.444 \pm 0.052$ \\
\hline $100 \mu \mathrm{M}$ & $0.629 \pm 0.038^{*}$ & $0.595 \pm 0.012^{* *}$ \\
\hline $200 \mu \mathrm{M}$ & $0.672 \pm 0.021^{* *}$ & $0.775 \pm 0.037^{* *}$ \\
\hline
\end{tabular}

a $P z$ value means the ratio of the colony diameter per the diameter of colony plus precipitation zone. ${ }^{*}, p<0.01 ;{ }^{* *}$ $p<0.001$.

Indinavir, ritonavir, amprenavir and tipranavir promoted a powerful dose-dependent inhibition of Sap production in C. albicans cultured in a defined medium containing BSA as the sole nitrogen source, at an acidic $\mathrm{pH}[33,79,86]$. Indinavir-treated $\mathrm{C}$. neoformans significantly affected the production of capsular polysaccharide, aspartic-type protease and urease, but not phospholipase and melanin [63,87]. Furthermore, the treatment of both $C$. neoformans and $C$. albicans yeasts with tipranavir significantly reduced the phospholipase activity [79]. Regarding C. neoformans, tipranavir moderately reduced the capsule size, while it had no influence on production of either urease or melanin [79]. Similar results on the reduction of $C$. neoformans' capsule thickness were reported by other HIV PIs, such as saquinavir $(170 \mu \mathrm{g} / \mathrm{mL})$, darunavir $(100 \mu \mathrm{g} / \mathrm{mL})$ and ritonavir $(120 \mu \mathrm{g} / \mathrm{mL})$ [88]. Ritonavir $(100 \mu \mathrm{g} / \mathrm{mL})$ blocked the production of extracellular aspartic proteases in T. asahii and T. inkin after growth for 48 and $72 \mathrm{~h}$ [73]. The pre-treatment of F. pedrosoi conidia with HIV PIs, particularly saquinavir, ritonavir and nelfinavir, notably arrested the secretion of pepstatin A-sensitive aspartic protease, inhibiting this activity by around 50, 40 and $30 \%$, respectively [41]. Additionally, ritonavir and nelfinavir inhibited lipolytic activities (esterase and phospholipase) by around 70\%, while indinavir and saquinavir restrained these substrates' hydrolyses by approximately $30 \%$ [41].

\subsection{Lopinavir Influences the Biofilm on Abiotic Surface}

It is well recognized that either surface or secreted molecules are directly implicated with the adhesion of $C$. albicans [84,89]. As reported herein, the treatment of $C$. albicans yeasts with lopinavir drastically alters the surface architecture, for example, removing glycomolecules involved with adhesive events to both abiotic and biotic substrates and interfering on the secretion of molecules, including hydrolytic enzymes. Corroborating all these premises, in the present study, the treatment with lopinavir decreased the ability of $C$. albicans to form a robust biofilm over a polystyrene surface, as judged by the significant reduction in the biomass parameter when yeasts were pre-treated or co-incubated with lopinavir at both tested concentrations (Figure 8, upper graphic). However, mature biofilm was not disarticulated by the lopinavir treatment (Figure 8, upper graphic). Regarding the metabolic activity of the fungal cells forming the biofilm, lopinavir was able to reduce the viability when incubated along all of the biofilm formation period as well as when added to the mature biofilm (Figure 8, lower graphic). 


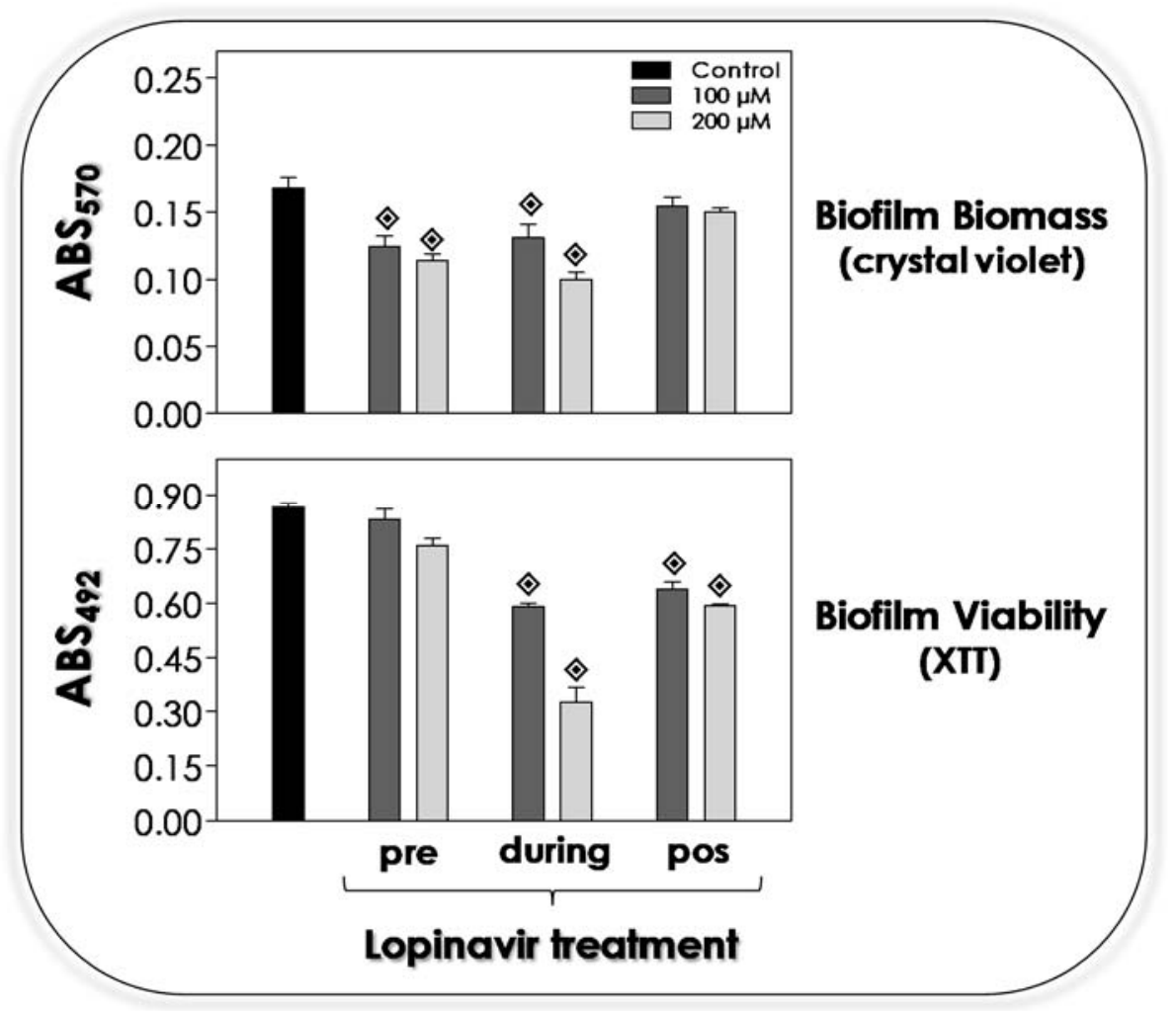

Figure 8. Effects of lopinavir on the biofilm of C. albicans. Yeasts were submitted to distinct lopinavir treatment as follows: fungi were pre-treated or not with lopinavir at 100 or $200 \mu \mathrm{M}$ for $20 \mathrm{~h}$ and then added to the polystyrene substrate for additional $48 \mathrm{~h}$ (pre); fungi were plated at the same time to adhere to the polystyrene substrate in the absence or in the presence of lopinavir and then the systems were incubated for $48 \mathrm{~h}$ (during); and fungi were first adhered to polystyrene for $48 \mathrm{~h}$, and then the mature biofilm was treated with lopinavir for additional $20 \mathrm{~h}$ (pos). Subsequently, the spent media were aspirated, and non-adherent cells were removed by thoroughly washing the biofilms with PBS. Biofilm was quantified using two methods to measure biomass (crystal violet staining and quantified by measuring the absorbance at $570 \mathrm{~nm}$ ) and viability (XTT staining and quantified by measuring the absorbance at $492 \mathrm{~nm}$ ). Wells with media and no cells were included as blank wells. The values represent the mean \pm standard deviation of three independent experiments performed in triplicate. The symbols indicate the experimental systems considered statistically significant from the control ( $p<0.05$; Student's $t$-test).

The adhesion to abiotic surfaces is the first step to microbial colonization and biofilm formation [90]. Tsang and Hong [91] reported that the pre-treatment of $C$. albicans yeasts with saquinavir $(100 \mu \mathrm{M})$, ritonavir $(100 \mu \mathrm{M})$ and indinavir $(20 \mu \mathrm{M})$ reduced $50 \%$ of the adhesion to acrylic strips, which is a common component of oral appliances, that was preincubated with pooled human saliva. Amprenavir-treated C. albicans cells had their ability to form biofilm biomass reduced in 50\% compared to non-treated yeasts [33]. Ritonavir $(100 \mu \mathrm{M})$ was able to arrest the biofilm formation in both T. asahii and T. inkin. In that last study, after $48 \mathrm{~h}$ of biofilm formation in the presence of ritonavir, fungal viability was drastically diminished (95\%) in all Trichosporon strains used, while biomass was reduced in $65 \%$ for T. inkin and $79 \%$ for T. asahii. However, ritonavir did not alter the viability of mature biofilm formed by Trichosporon spp. [73]. Relevantly, SEM images of Trichosporon biofilm evidenced a multilayer structure, which was destroyed after the treatment with ritonavir, showing weakly associated sparse cells. Confocal laser scanning microscopy permitted the visualization of the 3D biofilm architecture, which revealed that ritonavir $(100 \mu \mathrm{M})$ promoted a significant diminution in the biofilm thickness of T. asahii $(83 \%)$ and T. inkin (53\%), leading to the formation of thinner and fragile biofilms [73]. 


\subsection{Lopinavir Blocks the In Vitro Adhesion to Epithelial Cells}

The precondition for microbial colonization and successful infection is the adherence event to the host surfaces/structures. Due to the extraction of the external fibril layer of yeast cells by the treatment with lopinavir, several relevant molecules related to adhesion were also taken out (e.g., mannoproteins and Saps), resulting in a serious obstacle to $C$. albicans' colonization, such as inability to form biofilm over the inert polystyrene surface (Figure 8). The interaction with host cells is also coupled up to surface C. albicans molecules, such as mannose-riche glycoconjugates (e.g., mannoproteins) [89]. So, as already expected, lopinavir-treated yeasts notably reduced their adhesion to HEp-2 epithelial cells compared to non-treated yeasts (Figure 9).

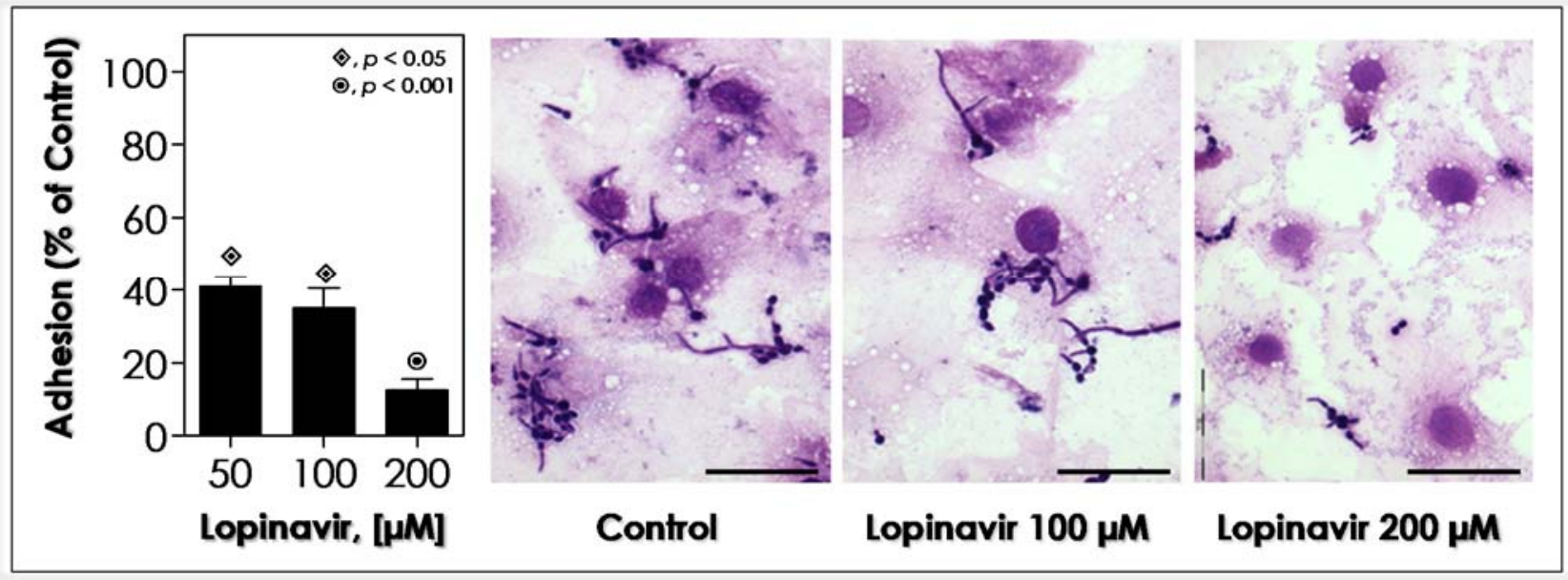

Figure 9. Effect of lopinavir on the interaction process between C. albicans and epithelial cells (HEp-2 lineage). In this set of experiments, untreated and lopinavir-treated yeasts were added to the monolayer in a ratio of 10:1 (fungi:epithelial cell), and then the systems were incubated at $37^{\circ} \mathrm{C}$ in $5 \% \mathrm{CO}_{2}$ for $1 \mathrm{~h}$. Systems were washed with PBS, fixed in Bouin's solution and stained with Giemsa. The percentage of infected epithelial cells was determined by randomly counting at least 200 animal cells in a light microscopy. The values represent the mean \pm standard deviation of three independent experiments performed in triplicate. The symbols indicate the experimental systems considered statistically significant from the control (Student's $t$-test). Representative images of the interaction process are shown. Bars $=20 \mu \mathrm{M}$.

Ritonavir, saquinavir and indinavir were able to block the adhesion process of $C$. albicans yeasts to human vaginal epithelial cancer cell line HeLa S3 by around 55\%, 50\% and $30 \%$, respectively, when used at $500 \mu \mathrm{M}$ [92]. Additionally, the addition of ritonavir and saquinavir at $200 \mu \mathrm{M}$ reduced the adherence of $C$. albicans to Vero cells by approximately $70 \%$ and $50 \%$, respectively, while indinavir was completely ineffective to interfere in the adhesion process [93]. Compared to our results, even taking into account that different epithelial cell lines were used, lopinavir was able to inhibit the fungal adhesion process by approximately $60 \%$ at a lower concentration $(50 \mu \mathrm{M})$ than that used to reach compatible inhibitory indices by both ritonavir and saquinavir. In order to evaluate the specificity of the adherence inhibition caused by ritonavir, a competitive binding experiment was conducted, and the addition of ritonavir to a mixture of purified Sap1-3 proteins prior to adding the C. albicans yeasts to interact to Vero cells completely abolished the inhibition of adherence promoted by the treatment with ritonavir alone [93]. Furthermore, saquinavir $(0.3 \mu \mathrm{M})$ drastically attenuated the injuries caused by C. albicans infection in an established in vitro model of oral candidiasis based on reconstituted human epithelium, reducing the cytopathic effects such as vacuolation, edema and detachment of the epithelial layers, as well as fungal invasion [94]. If HIV PIs inhibit fungal adherence, they might prevent candidiasis, since without attachment, the growth rate of $C$. albicans could be insufficient (making the quorum sensing signaling unfeasible) to maintain the tissue colonization and to provoke the tissue damage; also, the fungal cells would simply be washed away in 
the fluids that constantly bathe the mucosal membranes. Corroborating these findings, $C$. albicans mutants that are less adherent are also less virulent [95]. Consequently, a drug able to block the adhesion event could be an attractive anti-virulence and antifungal agent.

The pre-exposition of $C$. neoformans yeasts to indinavir $(10 \mu \mathrm{M})$ for $72 \mathrm{~h}$ followed by the interaction with murine microglial cell line BV2, used as prototype of immune effectors' cells, culminated in a higher phagocytosis extent compared to the untreated yeasts. In parallel, phagocytosed yeasts were killed by BV2 cells in a higher proportion than the untreated yeasts [63]. In this same line of research, Monari et al. [87] reported that both peripheral blood mononuclear cells and polymorphonuclear leukocytes killed indinavir-treated C. neoformans more efficiently than they killed untreated yeasts, which was a process associated with improved production of reactive oxygen species from both cell types. Interestingly, the treatment of C. albicans and C. neoformans with tipranavir induced contradictory results regarding the interaction with human neutrophils: $C$. neoformans yeasts were more susceptible to the killing by neutrophils than the untreated yeasts; meanwhile, it did not happen for C. albicans yeasts [79].

The pre-treatment of $F$. pedrosoi conidia with nelfinavir, saquinavir, indinavir or ritonavir provoked a typically concentration-dependent inhibition pattern on the interaction with Chinese human ovary $(\mathrm{CHO})$ epithelial cells. Relevantly, saquinavir was the most potent inhibitor of both adhesion and endocytosis processes, where the inhibition increased from 60 to $85 \%$ (adhesion index) and 70 to $97 \%$ (endocytic index) as saquinavir concentration rose from 50 to $200 \mu \mathrm{M}$ [34]. Moreover, both adhesion and endocytic indexes were considerable reduced taking into consideration the interaction process of HIV PIs-treated $F$. pedrosoi conidial cells with either fibroblasts or macrophages. HIV PIs also improved the macrophage killing capacity against $F$. pedrosoi [34]. Lopinavir at $100 \mu \mathrm{M}$ diminished the interaction process between $P$. verrucosa conidia and macrophages at about $50 \%$. In addition, the combination of lopinavir $(50 \mu \mathrm{M})$ plus ritonavir $(12.5 \mu \mathrm{M})$ affected the adhesion index, reducing it by approximately $40 \%$ [67]. Furthermore, the killing capability of macrophages against $P$. verrucosa conidia was significantly enhanced in the presence of lopinavir and ritonavir, individually and in combination [67].

\subsection{Lopinavir Contains the In Vivo Infection in Immunocompetent Mice}

Based on all the in vitro beneficial effects caused by lopinavir on C. albicans cells, we decided to evaluate its efficacy on in vivo infection by using a well-established murine model [96]. Firstly, immunocompetent BALB/c mice were intravenously infected with $C$. albicans yeasts, and $1 \mathrm{~h}$ after the inoculation, the animals were treated with PBS (positive control of infection), fluconazole (a classical antifungal used to treat candidiasis, including in this animal model) and lopinavir (the test drug). No animals died after 5 days postinfection; therefore, the infection was evaluated by counting the number of CFUs in three target organs: kidneys, spleen and liver. The results demonstrated that fluconazole, even at the lower concentration, was able to decrease the CFU drastically in the kidney, the main target organ in this animal model, when compared to the treatment with PBS (Figure 10). Similarly, lopinavir significantly diminished the infection in the kidney in a dose-dependent fashion. The infection in the liver was controlled by both fluconazole and lopinavir at both employed concentrations (10 or $15 \mathrm{mg} / \mathrm{mL}$ ). Spleen infection was significantly reduced only when using fluconazole or lopinavir at the highest concentration (Figure 10). 


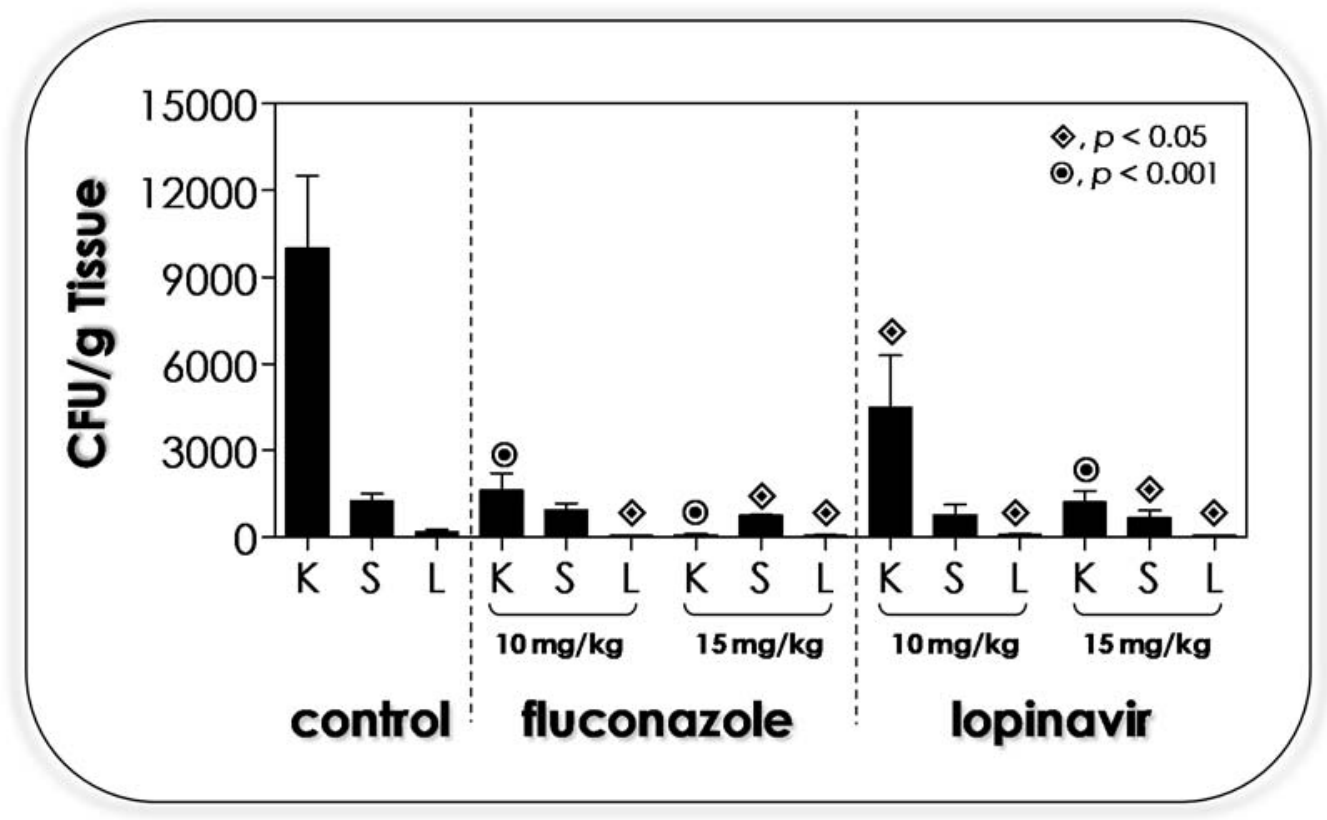

Figure 10. Effects of lopinavir on the in vivo infection of immunocompetent mice with $C$. albicans. Six female BALB/c mice per group were intravenously infected with $10^{5}$ yeasts. After $1 \mathrm{~h}$, the animals were treated with PBS (control group), fluconazole (at both 10 and $15 \mathrm{mg} / \mathrm{mL}$ ) and lopinavir (at both 10 and $15 \mathrm{mg} / \mathrm{mL}$ ). To evaluate the fungal burden, after 5 days post-infection, the animals were anaesthetized and euthanized, and then the kidneys (K), spleen (S) and liver (L) of the mice were dissected, weighed, homogenized in PBS and inoculated in BHI medium to evaluate the number of CFUs. The values represent the mean \pm standard deviation of three independent experiments performed in triplicate. The symbols indicate the experimental systems considered statistically significant from the control (ANOVA followed by Tukey-Kramer post-test).

Our study is the first one to demonstrate the efficaciousness of an HIV PI in curing the disseminated infection caused by C. albicans in an in vivo animal model. Previously, Cassone et al. [86] showed that indinavir and ritonavir (both used at $10 \mu \mathrm{M}$ ) presented a therapeutic effect in an experimental model of vaginal candidiasis (estrogen-dependent rat vaginitis), with an efficacy comparable to fluconazole, inducing a rapid clearance of the C. albicans from the vagina of experimentally infected rats, as shown by the reduction in CFU counts on day 2 after vaginal challenge. Those authors proposed that Sap inhibitors may decisively affect the burden of Candida cells present on the vaginal mucosa, and this in turn may favor immunoreconstitution. Corroborating this statement, low burdens of virulent $C$. albicans cells induced a protective response rich in Th1 cells [97]. BALB/c mice intravenously infected with C. neoformans and subsequently treated with $14.5 \mathrm{mg} / \mathrm{kg}$ of tipranavir or $25 \mu \mathrm{M}$ of indinavir (intravenously administrated daily for 10 days) showed a significant decrease in CFUs from the brain and liver of animals as observed 15 days after challenge. Interestingly, histological examination of the brain from immunocompetent mice evidenced a smaller capsule size, which is a main virulence factor of this fungal pathogen, in tipranavir-treated mice with respect to the untreated ones [79].

\subsection{Lopinavir Contains the In Vivo Infection in Immunosuppressed Mice}

The most problematic issue concerning the candidiasis is related to the host immunosuppressant status. In alignment with this knowledge, we repeated the in vivo infection using cyclophosphamide-immunosuppressed BALB/c mice. Using the same protocol described for immunocompetent animals, we reported a completely distinct pattern of infection, since all the immunosuppressed animals died along the 5 days after being inoculated with C. albicans yeasts (Figure 11A). Fluconazole $(10 \mathrm{mg} / \mathrm{mL})$ was able to protect all the animals, and no death was detected after 5 days of infection (100\% of survival), 
while lopinavir $(10 \mathrm{mg} / \mathrm{mL}$ ) promoted a rate of $80 \%$ survivability (Figure $11 \mathrm{~A})$. In animals treated with a combination of fluconazole plus lopinavir, as expected and in consideration of the results herein exposed, this treatment promoted $100 \%$ of animals' survival (Figure 11A). The infection was also monitored by counting the CFUs in the key organs (Figure 11B). Interesting to highlight, the immunosuppression provoked a more robust infection in BALB/c mice (3.5-fold high) in relation to the immunocompetent ones (compare the Figures 10 and $11 \mathrm{~B}$, control systems). The drug treatment revealed that (i) fluconazole alone $(10 \mathrm{mg} / \mathrm{mL})$ severely reduced the infection in the kidney, but did not change the liver and spleen infections; (ii) lopinavir alone $(10 \mathrm{mg} / \mathrm{mL})$ significantly diminished the infections in both kidney and spleen, but not in the liver; and (iii) the fluconazole combined with lopinavir $(10 \mathrm{mg} / \mathrm{mL}$ of each one drug) resulted in a robust reduction in infection in all evaluated organs (Figure 11B). Histopathology sections of the kidney (the key organ during the $C$. albicans infection in the murine model) corroborated the CFU counts, in which PBS-treated animals presented several nests of fungi compared to fluconazole-, lopinavirand fluconazole+lopinavir-treated animals (Figure 11C).

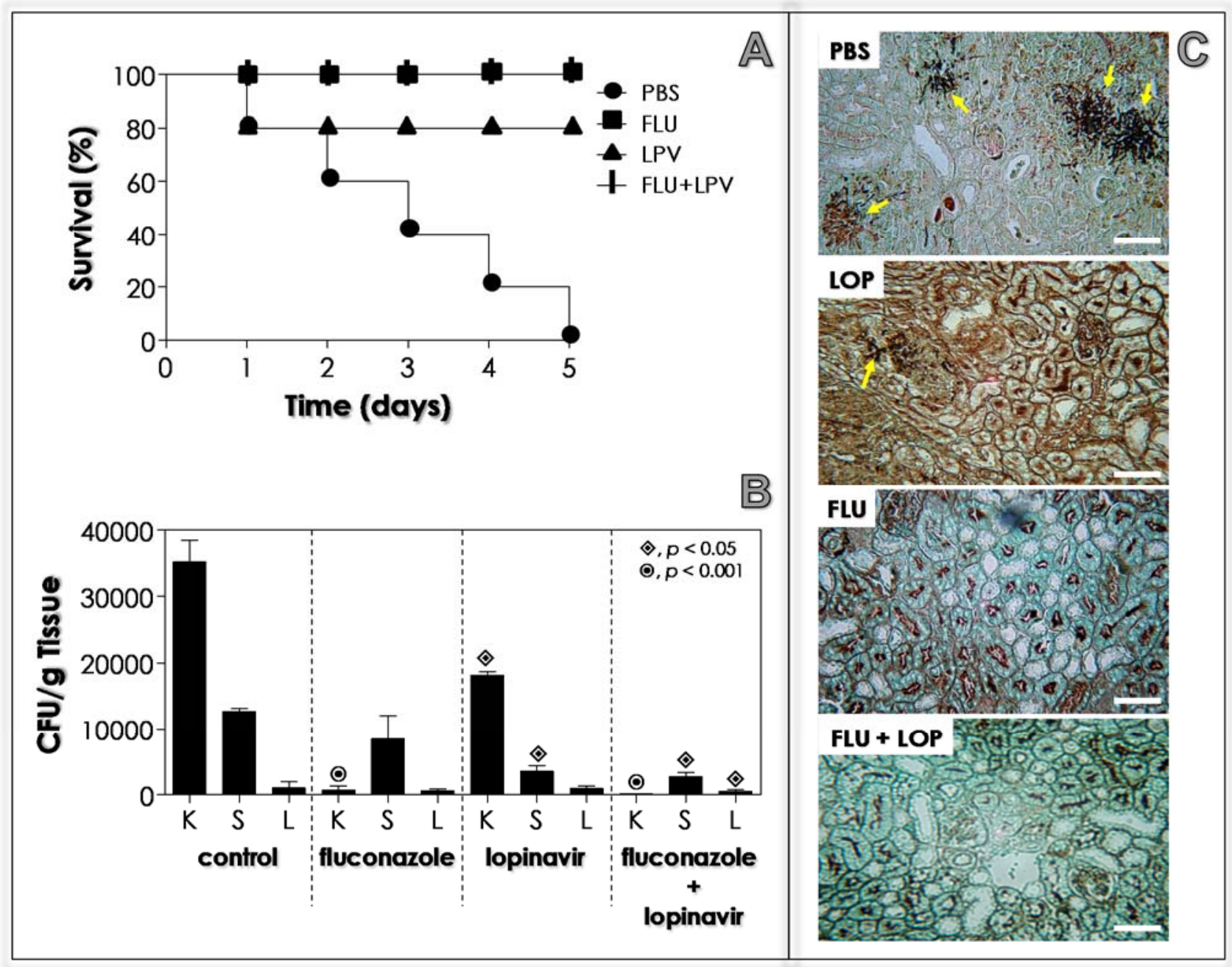

Figure 11. Effects of lopinavir on the in vivo infection of immunosuppressed mice with C. albicans. Six cyclophosphamideimmunosuppressed female BALB/c mice per group were intravenously infected with $10^{5}$ yeasts. After $1 \mathrm{~h}$, the animals were treated with PBS (control group), fluconazole (FLU; $10 \mathrm{mg} / \mathrm{mL}$ ), lopinavir (LPV; $10 \mathrm{mg} / \mathrm{mL}$ ) and a combination of both drugs at $10 \mathrm{mg} / \mathrm{mL}$ (FLU + LPV). (A) The mice survivability was evaluated every day during 5 consecutive days to construct a survival curve. (B) To evaluate the fungal burden, after 5 days post-infection, the animals were anaesthetized and euthanized, and then the kidneys (K), spleen (S) and liver (L) of the mice were dissected, weighed, homogenized in PBS and inoculated in BHI medium to evaluate the number of CFUs. Note: The time of animal death occurred throughout the 
day (some died in the morning, others in the afternoon or in the evening). In this context, the animals were checked every day at three different times: in the morning (at 8:00 a.m.), in the afternoon (at 13:00 p.m.) and in the evening (at 18:00 p.m.) in order to construct the survival curve. So, on the fifth post-infection day, the live animals after the first inspection (in the morning) were selected to analyze the infection on the target organs. The values represent the mean \pm standard deviation of three independent experiments performed in triplicate. The symbols indicate the experimental systems considered statistically significant from the control (ANOVA followed by Tukey-Kramer post-test); (C) Representative histological images of kidneys after Grocott-Gomori's methenamine silver staining. The yellow arrows indicate the fungal nests. Bars $=10 \mu \mathrm{M}$.

Similarly, female immunocompromised BALB/c mice challenged with intravenous inoculation of $C$. neoformanas ( $10^{8}$ yeasts) previously exposed to indinavir showed prolonged survival and reduced fungal burden in target organs (liver and brain) with respect to mice infected with untreated C. neoformans [98]. Those beneficial results were accompanied by pronounced activation of murine splenic dendritic cells, which induced positive modulation of activatory and costimulatory molecules (e.g., CD86 and CD40) and generated an enhanced secretion of interleukin (IL)-12 and nitric oxide (NO), as well as promoted an increased secretion of IL-2, interferon- $\gamma$ and proliferation in response to fungal antigens by splenic T cells [98]. Collectively, the reported immunological profile might be a determinant to T lymphocyte cells towards the Th1 response that is considered protective against $C$. neoformans infection [99].

\subsection{Lopinavir Reduces the Sap Production by Yeasts Recovered from Kidney of Infected Mice}

Yeasts recovered from kidneys of infected immunosuppressed animals and treated with PBS, fluconazole $(10 \mathrm{mg} / \mathrm{mL})$, lopinavir $(10 \mathrm{mg} / \mathrm{mL})$ and fluconazole + lopinavir (10 $\mathrm{mg} / \mathrm{mL}$ of each one drug) were grown in YCB-BSA medium to detect the ability to produce Sap1-3 in comparison to the yeasts not challenged to in vivo infection (Figure 12). Sap1-3 antigen was detected in higher amounts in yeasts recovered from kidneys of animals treated with PBS than the yeasts only cultivated in the in vitro culture medium. Yeasts recovered from animals treated with fluconazole presented the same amount of Sap1-3 antigens compared with yeasts only cultured in in vitro conditions. Relevantly, $C$. albicans yeasts recovered from animals treated with lopinavir or fluconazole + lopinavir had a significant reduction in the production of Sap1-3 antigens compared to the in vitro cultivating yeasts (Figure 12).

An important clinical observation is the decreased occurrence of oral candidiasis in HIV PI-treated individuals [9]. It was speculated that a direct elimination of Candida Saps may have a supportive role in this phenomenon, since it has been shown that inhibition of Sap activity by treatment with aspartic PIs resulted in reduced adherence and virulence [59]. Our experiments corroborated this clinical appointment, since C. albicans recovered from infected animals treated with lopinavir had a significant decrease in the expression of Sap antigens. In a very interesting work, Cassone et al. [100] compared the level of Candida Saps in the saliva of patients receiving two distinct therapies: one group was treated with HAART containing HIV PIs (PI-HAART), and another one treated with HAART containing non-nucleoside reverse-transcriptase inhibitors (NNRTIs). The percentage of Sap-positive, Candida-positive subjects and the mean of Sap amount decreased substantially, from 100\% to $55 \%$ and from 271 to $152 \mathrm{ng}$ of Sap/mL of saliva, respectively, after only 14 days of PI-HAART administration. Along that trend, the Saps were present in only 3 of 8 Candidapositive subjects after 30 days, to become undetectable in any subject after 90 and 180 days from treatment initiation. Contrarily, in the NNRTI-HAART group, neither the number of Sap-positive subjects among Candida-positive subjects nor the amount of the enzyme was seen to decrease significantly over the duration of treatment [100]. De Bernardis et al. [101] corroborated that HAART-PI, but not HAART-NNRTI, strongly inhibited Sap expression in the oral cavity without exerting any consistent effect on the role of Candida spp. isolation or selection of low virulence or antifungal resistant fungus biotype. Early anti-Sap effects 
and, somewhat later, immunoreconstitution, could favorably interact to make PI-HAART beneficial against candidiasis [102].

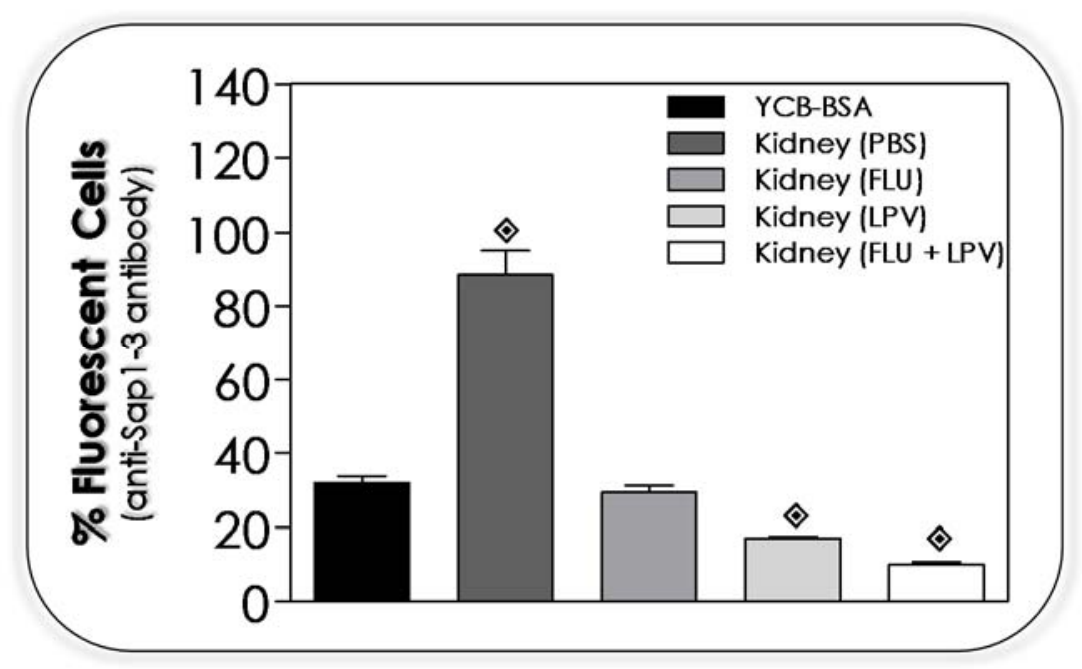

Figure 12. Effects of lopinavir on the expression of Sap1-3 antigens in C. albicans before and after passage in BALB/c mice. Yeast colonies isolated from the kidneys of infected mice, which were treated with PBS, fuconazole $(10 \mathrm{mg} / \mathrm{mL})$, lopinavir $(10 \mathrm{mg} / \mathrm{mL})$ and fluconazole + lopinavir (both at $10 \mathrm{mg} / \mathrm{mL}$ ) were grown in YCB-BSA medium at $37^{\circ} \mathrm{C}$ for $48 \mathrm{~h}$, and then the expression of Sap antigens was evaluated by flow cytometry using an antibody raised against Sap1-3. Yeasts only grown in axenic conditions were run in parallel as a control. The percentage of Sap1-3-labeled yeasts is shown. The values represent the mean \pm standard deviation of three independent experiments performed in triplicate. The symbols indicate the experimental systems considered statistically significant from the control (yeasts grown in vitro in YCB-BSA medium) ( $p<0.05$; ANOVA followed by Tukey-Kramer post-test).

A recent work revealed that lopinavir exhibited potent synergistic interactions with azole drugs, particularly with itraconazole, against the emergent, opportunistic and multidrug-resistant Candida auris [103]. Those authors studied the mechanisms of action of these drugs working together, and they proposed by using comparative transcriptomic profiling that lopinavir operates as an azole chemosensitizing agent, since it is able to interfere with the glucose permeation and ATP synthesis, which compromised the efficacy of efflux pumps to eject azoles to the extracellular medium; as a consequence, it reverts the well-known azole resistance profile in C. auris. Furthermore and similar to our in vivo experiments, the lopinavir/itraconazole combination enhanced the survival rate of C. aurisinfected Caenorhabditis elegans by $90 \%$ and reduced the fungal burden in infected nematodes by $88.5 \%$ compared to the untreated control [103]. Together, these results endorse that lopinavir is a multimodal drug, operating and triggering multiple responses/actions in biological systems.

\section{Conclusions}

Drug repurposing represents a promising approach to drug discovery, since the identification of novel applications among already existing drugs significantly reduces the time, efforts and expenses needed in comparison to the development of novel drugs. This scenario is particularly important for antimicrobial therapies, once the emergence of multidrug resistant microorganisms is increasingly common, threatening people all over the world and being a challenge to clinicians. As success examples, we can cite the antifungal agent amphotericin B that was latter licensed for leishmaniasis' treatment [104], and azidothymidine (AZT) that was developed but not approved to treat cancer and was posteriorly licensed for HIV therapy [105,106]. Besides, many other studies have been conducted over time. For example, the antiviral drug valganciclovir has improved 
the survival of patients with secondary glioblastoma [107], while anti-cancer drugs are promising against bacterial infections [108].

In the present study, by using multiple experimental approaches, it was demonstrated that the action of lopinavir on C. albicans attenuated crucial biological events (e.g., nutrition, proliferation, morphogenesis and morphological homeostasis) as well as interfered in processes indirectly/directly related to the establishment of a successful infection (e.g., inhibition of hydrolytic activity of Saps, which are the main virulence factors of this fungus, blockage of synthesis/production of several other virulence attributes, including lipases and mannoproteins, interference on fundamental adhesive surface properties that culminated in inability to form biofilm in inert surface and to interact with epithelial cells). All these in vitro beneficial effects of lopinavir culminated with its ability to control disseminated infection in an in vivo animal model taking into consideration either immunocompetent or immunocompromised mice. Considering the concomitant recurrence of HIV- and C. albicans-related infectious diseases and that their major virulence factors, namely HIV-1 protease and C. albicans Sap2, respectively, belong to the same superfamily of aspartic proteases, the development of new dual inhibitors able to interact with both targets represents an enormous challenge and a matter of high relevance.

Collectively, our results highlight that lopinavir may be used as promising repurposing drug against $C$. albicans infection as well as may be used as a lead compound for the development of novel antifungal drugs. In this context, the generation of more-specific aspartic PIs with high selective toxicity against Sap-producing fungi would probably represent a valid therapeutic strategy in the battle to get novel (presenting new mechanisms of action) and effective antifungal drugs. Particularly, the beneficial effects of combining lopinavir and azoles (e.g., fluconazole) highlight a promising and relevant line of future research, due to the possibility to reduce the probability of resistant strains emerging and to minimize the drugs' toxicity and their side effects.

Supplementary Materials: The following are available online at https:/ /www.mdpi.com/article/10 .3390/jof7060424/s1, Figure S1. Production of aspartic proteases secreted by Candida albicans (strain 11). (A) The enzymatic activity was evidenced after $96 \mathrm{~h}$ of in vitro growth in YCB-BSA agar plates by the presence of a large clear zone around the fungal colony, which corresponds to the hydrolysis of the albumin present in the solid medium. (B) The BSA consumption profile along the in vitro growth of C. albicans yeasts in YCB-BSA liquid medium was shown. After 24, 48, 72 and $96 \mathrm{~h}$, the fungal cultures were harvested, filtered and the spent culture media were analyzed by SDS-PAGE to demonstrate the cleavage of soluble BSA along the time. A control in which the culture medium was collected before the yeast inoculation was added in the same gel (lane 0 ). The gel was silver stained and the intact BSA molecule $(66 \mathrm{kDa})$ was shown. Note the gradual BSA fragmentation into smaller peptides. (C) Pepstatin A, a classical aspartic protease inhibitor, at $10 \mu \mathrm{M}$ fully blocked the BSA cleavage by inhibiting the aspartic protease activities observed in the fungal secretion (line $\mathrm{BSA}+\mathrm{S}+\mathrm{P}$; compare with the line BSA+S, which represents the incubation of fungal secretions with intact BSA molecules). Line designated as BSA represents the intact BSA molecule incubated only with buffer (pH 4.0). (D) Western blotting assay revealed the presence of a polypeptide of $43 \mathrm{kDa}$ recognized by the anti-Sap1-3 antibody, which corresponds to the molecular mass of Sap2, the main Sap detected in C. albicans secretions under the employed conditions (White and Agabian 1995); Figure S2. (A) Standard ligand A70450 and lopinavir in different protonation states used for the molecular docking with Sap2. L1 (umprotonated) and L2 (protonated) correspond to different protonation states of lopinavir. Black arrows highlight the protonated quaternary nitrogen atom lopinavir. (B) Comparison of the geometries of the docked A70450 to SAP2 as determined experimentally (carbon atoms in gray) and by molecular docking (carbon atoms in cyan), when both D32 and the nitrogen atom in the ligand six-membered ring are considered protonated. Sap2 interacting residues are highlighted; potential hydrogen bonds are shown by orange dashed lines. Remaining atoms are color-coded as oxygen: red, nitrogen: blue, hydrogen: white. (Except for the polar hydrogen of D32, the remaining protein hydrogen atoms were removed for clarity). 
Author Contributions: All authors conceived and designed the experiments. A.L.S.S., L.A.B.-S., D.S.G., L.S.R., S.S.C.O., L.O.P.S., V.S.O., R.D.L., M.R.P. and J.E.M. performed the experiments. All authors analyzed the data. A.L.S.S., R.D.L., C.P.T. and M.H.B. contributed reagents/materials/analysis tools. All authors wrote and revised the paper. All authors agree to be accountable for all aspects of the work. All authors have read and agreed to the published version of the manuscript.

Funding: This work was supported by grants from Fundação Carlos Chagas Filho de Amparo à Pesquisa do Estado do Rio de Janeiro (FAPERJ), Fundação de Amparo à Pesquisa do Estado de São Paulo (FAPESP), Fundação de Amparo a Ciência e Tecnologia do Estado de Pernambuco (FACEPE), Conselho Nacional de Desenvolvimento Científico e Tecnológico (CNPq) and Coordenação de Aperfeiçoamento de Pessoal de Nível Superior (CAPES—Financial code 001).

Institutional Review Board Statement: The study was conducted according to the guidelines of the Declaration of Helsinki, and approved by the Ethics Committee of the Universidade de São Paulo (USP) (protocol code 042-127-02).

Informed Consent Statement: Not applicable.

Data Availability Statement: Not applicable.

Acknowledgments: The authors would like to thank Denise Rocha de Souza (UFRJ) for technical assistance in the experiments.

Conflicts of Interest: The authors declare no conflict of interest.

\section{References}

1. Ohmit, S.E.; Sobel, J.D.; Schuman, P.; Duerr, A.; Mayer, K.; Rompalo, A.; Klein, R.S.; HIV Epidemiology Research Study (HERS) Group. Longitudinal Study of Mucosal Candida Species Colonization and Candidiasis among Human Immunodeficiency Virus (HIV)-Seropositive and At-Risk HIV-Seronegative Women. J. Infect. Dis. 2003, 188, 118-127. [CrossRef]

2. Palella, F.J., Jr.; Delaney, K.M.; Moorman, A.C.; Loveless, M.O.; Fuhrer, J.; Satten, G.A.; Aschman, D.J.; Holmberg, S.D. Declining morbidity and mortality among patients with advanced human immunodeficiency virus infection. N. Engl. J. Med. 1998, 338, 853-860. [CrossRef]

3. Portela, M.B.; Souza, I.P.R.; Costa, E.M.M.D.B.; Hagler, A.N.; Soares, R.M.A.; Santos, A.L.S. Differential Recovery of Candida Species from Subgingival Sites in Human Immunodeficiency Virus-Positive and Healthy Children from Rio de Janeiro, Brazil. J. Clin. Microbiol. 2004, 42, 5925-5927. [CrossRef] [PubMed]

4. Barchiesi, F.; Maracci, M.; Radi, B.; Arzeni, D.; Baldassarri, I.; Giacometti, A.; Scalise, G. Point prevalence, microbiology and fluconazole susceptibility patterns of yeast isolates colonizing the oral cavities of HIV-infected patients in the era of highly active antiretroviral therapy. J. Antimicrob. Chemother. 2002, 50, 999-1002. [CrossRef] [PubMed]

5. Gottfredsson, M.; Cox, G.M.; Indridason, Ó.S.; De Almeida, G.M.D.; Heald, A.E.; Perfect, J.R. Association of Plasma Levels of Human Immunodeficiency Virus Type 1 RNA and Oropharyngeal Candida Colonization. J. Infect. Dis. 1999, 180, 534-537. [CrossRef]

6. Gajdács, M.; Dóczi, I.; Ábrók, M.; Lázár, A.; Burián, K. Epidemiology of candiduria and Candida urinary tract infections in inpatients and outpatients: Results from a 10-year retrospective survey. Cent. Eur. J. Urol. 2019, 72, 209-214. [CrossRef]

7. Bhattacharya, S.; Sae-Tia, S.; Fries, B.C. Candidiasis and Mechanisms of Antifungal Resistance. Antibiotics 2020, 9, 312. [CrossRef]

8. Selmecki, A.; Forche, A.; Berman, J. Genomic Plasticity of the Human Fungal Pathogen Candida albicans. Eukaryot. Cell 2010, 9 , 991-1008. [CrossRef] [PubMed]

9. Patton, L.L.; van der Horst, C. Oral infections and other manifestations of HIV disease. Infect. Dis. Clin. N. Am. 1999, 13, 879-900. [CrossRef]

10. Dios, P.D.; Ocampo, A.; Miralles, C.; Otero, I.; Iglesias, I.; Rayo, N. Frequency of oropharyngeal candidiasis in HIV-infected patients on protease inhibitor therapy. Oral Surg. Oral Med. Oral Pathol. Oral Radiol. Endodontol. 1999, 87, 437-441. [CrossRef]

11. Dios, P.D.; Hermida, A.O.; Llerena, N.R.; Martin, I.I.; Varela, I.O.; Vazquez, C.M. Effect of Plasma Human Immunodeficiency Virus Type 1 RNA Levels on Neutrophil Oxidative Burst. J. Infect. Dis. 2000, 181, 1214-1215. [CrossRef]

12. Patton, L.L.; McKaig, R.; Strauss, R.; Rogers, D.; Eron, J.J., Jr. Changing prevalence of oral manifestations of human immunodeficiency virus in the era of protease inhibitor therapy. Oral Surg. Oral Med. Oral Pathol. Oral Radiol. Endodontol. 2000, 89, 299-304. [CrossRef]

13. Ho, D.D.; Neumann, A.U.; Perelson, A.S.; Chen, W.; Leonard, J.M.; Markowitz, M. Rapid turnover of plasma virions and CD4 lymphocytes in HIV-1 infection. Nat. Cell Biol. 1995, 373, 123-126. [CrossRef]

14. Wendland, T.; Furrer, H.; Vernazza, P.L.; Frutig, K.; Christen, A.; Matter, L.; Malinverni, R.; Pichler, W.J. HAART in HIV-infected patients: Restoration of antigen-specific CD4 T-cell responses in vitro is correlated with CD4 memory T-cell re-constitution, whereas improvement in delayed type hypersensitivity is related to a decrease in viraemia. AIDS 1999, 13, 1857-1862. [CrossRef] 
15. Mastroianni, C.M.; Lichtner, M.; Mengoni, F.; D'Agostino, C.; Forcina, G.; D’Ettorre, G.; Santopadre, P.; Vullo, V. Improvement in neutrophil and monocyte function during highly active antiretroviral treatment of HIV-1-infected patients. AIDS 1999, 13, 883-890. [CrossRef]

16. Pericolini, E.; Cenci, E.; Gabrielli, E.; Perito, S.; Mosci, P.; Bistoni, F.; Vecchiarelli, A. Indinavir influences biological function of dendritic cells and stimulates antifungal immunity. J. Leukoc. Biol. 2008, 83, 1286-1294. [CrossRef]

17. Powderly, W.G.; Landay, A.; Lederman, M.M. Recovery of the immune system with antiretroviral therapy: The end of opportunism? JAMA 1998, 280, 72-77. [CrossRef]

18. Sepkowitz, K.A. Effect of HAART on natural history of AIDS-related opportunistic disorders. Lancet 1998, 351, 228-230. [CrossRef]

19. Zingman, B.S. Resolution of Refractory AIDS-Related Mucosal Candidiasis after Initiation of Didanosine plus Saquinavir. N. Engl. J. Med. 1996, 334, 1674-1675. [CrossRef]

20. Cauda, R.; Tacconelli, E.; Tumbarello, M.; Morace, G.; De Bernardis, F.; Torosantucci, A.; Cassone, A. Role of Protease Inhibitors in Preventing Recurrent Oral Candidosis in Patients With HIV Infection: A Prospective Case-Control Study. JAIDS J. Acquir. Immune Defic. Syndr. 1999, 21, 20-25. [CrossRef]

21. Braga-Silva, L.A.; Santos, A.L.S. Aspartic protease inhibitors as potential anti-Candida albicans drugs: Impacts on fungal biology, virulence and pathogenesis. Curr. Med. Chem. 2011, 18, 2401-2419. [CrossRef] [PubMed]

22. Santos, A.L.S. Aspartic proteases of human pathogenic fungi are prospective targets for the generation of novel and effective antifungal inhibitors. Curr. Enzym. Inhib. 2011, 7, 96-118. [CrossRef]

23. Saag, M.S.; Gandhi, R.T.; Hoy, J.F.; Landovitz, R.J.; Thompson, M.A.; Sax, P.E.; Smith, D.M.; Benson, C.A.; Buchbinder, S.P.; Del Rio, C.; et al. Antiretroviral drugs for treatment and prevention of HIV infection in adults: 2020 recommendations of the International Antiviral Society-USA Panel. JAMA 2020, 324, 1651-1669. [CrossRef]

24. Otto, S.B.J.; George, P.E.; Mercedes, R.; Nabukeera-Barungi, N. Cryptococcal meningitis and immune reconstitution inflammatory syndrome in a pediatric patient with HIV after switching to second line antiretroviral therapy: A case report. BMC Infect. Dis. 2020, 20, 68. [CrossRef] [PubMed]

25. Braga-Silva, L.A.; Mesquita, D.G.; Ribeiro, M.D.; Carvalho, S.M.; Fracalanzza, S.E.; Santos, A.L.S. Trailing end-point pheno-type antibiotic-sensitive strains of Candida albicans produce different amounts of aspartyl peptidases. Braz. J. Med. Biol. Res. 2009, 42, 765-770. [CrossRef]

26. White, T.; Agabian, N. Candida albicans secreted aspartyl proteinases: Isoenzyme pattern is determined by cell type, and levels are determined by environmental factors. J. Bacteriol. 1995, 177, 5215-5221. [CrossRef]

27. Santos, A.L.S.; Carvalho, I.M.; Silva, B.A.; Portela, M.B.; Alviano, C.S.; Soares, R.M.A. Secretion of serine peptidase by a clinical strain of Candida albicans: Influence of growth conditions and cleavage of human serum proteins and extracellular matrix components. FEMS Immunol. Med. Microbiol. 2006, 46, 209-220. [CrossRef]

28. Trott, O.; Olson, A.J. AutoDock Vina: Improving the speed and accuracy of docking with a new scoring function, efficient optimization, and multithreading. J. Comput. Chem. 2010, 31, 455-461. [CrossRef] [PubMed]

29. Cutfield, S.M.; Dodson, E.J.; Anderson, B.F.; Moody, P.C.; Marshall, C.J.; Sullivan, P.A.; Cutfield, J.F.; Moody, P.; Moody, P.; Marshall, C. The crystal structure of a major secreted aspartic proteinase from Candida albicans in complexes with two inhibitors. Struct. 1995, 3, 1261-1271. [CrossRef]

30. Olsson, M.H.M.; Søndergaard, C.R.; Rostkowski, M.; Jensen, J.H. PROPKA3: Consistent Treatment of Internal and Surface Residues in Empirical pKa Predictions. J. Chem. Theory Comput. 2010, 7, 525-537. [CrossRef]

31. Morris, G.M.; Huey, R.; Olson, A.J. Using AutoDock for Ligand-Receptor Docking. Curr. Protoc. Bioinform. 2008, $24,8-14$. [CrossRef]

32. Burokerkilgore, M.; Wang, K. A Coomassie Brilliant Blue G-250-Based Colorimetric Assay for Measuring Activity of Calpain and Other Proteases. Anal. Biochem. 1993, 208, 387-392. [CrossRef]

33. Braga-Silva, L.A.; Mogami, S.S.; Valle, R.S.; Silva-Neto, I.D.; Santos, A.L.S. Multiple effects of amprenavir against Candida albicans. FEMS Yeast Res. 2010, 10, 221-224. [CrossRef]

34. Palmeira, V.F.; Kneipp, L.F.; Rozental, S.; Alviano, C.S.; Santos, A.L.S. Beneficial Effects of HIV Peptidase Inhibitors on Fonsecaea pedrosoi: Promising Compounds to Arrest Key Fungal Biological Processes and Virulence. PLoS ONE 2008, 3, e3382. [CrossRef]

35. Hazen, K.C.; Cutler, J.E. Autoregulation of germ tube formation by Candida albicans. Infect. Immun. 1979, 24, 661-666. [CrossRef]

36. Braga-Silva, L.A.; Santos, A.L.S.; Portela, M.B.; Souto-Padron, N.T.; Soares, R.M.A. Effect of suramin on the human pathogen Candida albicans: Implications on the fungal development and virulence. FEMS Immunol. Med. Microbiol. 2007, 51, 399-406. [CrossRef]

37. Soares, M.C.; Aléssio, M.L.; Léger, C.L.; Bluet-Pajot, M.T.; Clauser, H.; Enjalbert, A.; Kordon, C.; Wandscheer, D.E. Effect of essential fatty acid deficiency on membrane fatty acid content and growth hormone stimulation of rat pituitaries during postnatal development. J. Lipid Res. 1995, 36, 1401-1406. [CrossRef]

38. Folch, J.; Lees, M.; Sloane Stanley, G.H. A simple method for the isolation and purification of total lipids from animal tissues. J. Biol. Chem. 1957, 226, 497-509. [CrossRef]

39. Larsen, T.; Axelsen, J.; Ravn, H.W. Simplified and rapid method for extraction of ergosterol from natural samples and detection with quantitative and semi-quantitative methods using thin-layer chromatography. J. Chromatogr. A 2004, 1026, 301-304. [CrossRef] 
40. Granato, M.Q.; Gonçalves, D.S.; Seabra, S.H.; McCann, M.; Devereux, M.; Santos, A.L.S.; Kneipp, L.F. 1,10-Phenanthroline-5,6dione-based compounds are effective in disturbing crucial physiological events of Phialophora verrucosa. Front. Microbiol. 2017, 8 , 76. [CrossRef]

41. Palmeira, V.F.; Alviano, D.S.; Braga-Silva, L.A.; Goulart, F.R.V.; Granato, M.Q.; Rozental, S.; Alviano, C.S.; Santos, A.L.S.; Kneipp, L.F. HIV aspartic peptidase inhibitors modulate surface molecules and enzyme activities involved with physiopathological events in Fonsecaea pedrosoi. Front. Microbiol. 2017, 8, 918. [CrossRef]

42. Rüchel, R.; Tegeler, R.; Trost, M. A comparison of secretory proteinases from different strains of Candida albicans. Med. Mycol. 1982, 20, 233-244. [CrossRef]

43. Price, M.F.; Wilkinson, I.D.; Gentry, L.O. Plate method for detection of phospholipase activity in Candida albicans. Med. Mycol. 1982, 20, 7-14. [CrossRef]

44. Aktas, E.; Yigit, N.; Ayyildiz, A. Esterase Activity in Various Candida Species. J. Int. Med. Res. 2002, 30, 322-324. [CrossRef]

45. Peeters, E.; Nelis, H.J.; Coenye, T. Comparison of multiple methods for quantification of microbial biofilms grown in microtiter plates. J. Microbiol. Methods 2008, 72, 157-165. [CrossRef]

46. Gandra, R.M.; Silva, L.N.; Souto, X.M.; Sangenito, L.S.; Cruz, L.P.S.; Braga-Silva, L.A.; Gonçalves, D.S.; Seabra, S.H.; Branquinha, M.H.; Santos, A.L.S. The serine peptidase inhibitor TPCK induces several morphophysiological changes in the opportunistic fungal pathogen Candida parapsilosis sensu stricto. Med. Mycol. 2019, 57, 1024-1037. [CrossRef]

47. Muñoz, J.E.; Ramirez, L.M.; Dias, L.D.S.; Rivas, L.A.; Ramos, L.S.; Santos, A.L.S.; Taborda, C.P.; Parra-Giraldo, C.M. Pathogenicity levels of Colombian strains of Candida auris and Brazilian strains of Candida haemulonii species complex in both murine and Galleria mellonella experimental models. J. Fungi 2020, 6, 104. [CrossRef]

48. Rossi, D.C.; Muñoz, J.E.; Carvalho, D.D.; Belmonte, R.; Faintuch, B.; Borelli, P.; Miranda, A.; Taborda, C.P.; Daffre, S. Thrapeutic use of a cationic antimicrobial peptide from the spider Acanthoscurria gomesiana in the control of experimental candidiasis. BMC Microbiol. 2012, 12, 28. [CrossRef] [PubMed]

49. Andes, D.; Diekema, D.J.; Pfaller, M.A.; Prince, R.A.; Marchillo, K.; Ashbeck, J.; Hou, J. In vivo pharmacodynamic characterization of anidulafungin in a neutropenic murine candidiasis model. Antimicrob. Agents Chemother. 2008, 52, 539-550. [CrossRef] [PubMed]

50. Naglik, J.R.; Challacombe, S.J.; Hube, B. Candida albicans Secreted Aspartyl Proteinases in Virulence and Pathogenesis. Microbiol. Mol. Biol. Rev. 2003, 67, 400-428. [CrossRef] [PubMed]

51. Monika, S.; Malgorzata, B.; Zbigniew, O. Contribution of Aspartic Proteases in Candida Virulence. Protease Inhibitors against Candida Infections. Curr. Protein Pept. Sci. 2017, 18, 1050-1062. [CrossRef] [PubMed]

52. Na, B.K.; Song, C.Y. Use of monoclonal antibody in diagnosis of candidiasis caused by Candida albicans: Detection of circulating aspartyl proteinase antigen. Clin. Diagn. Lab. Immunol. 1999, 6, 924-929. [CrossRef] [PubMed]

53. Stewart, K.; Abad-Zapatero, C. Candida proteases and their inhibition: Prospects for antifungal therapy. Curr. Med. Chem. 2001, 8, 941-948. [CrossRef] [PubMed]

54. Monod, M.; Borg-von, Z.M. Secreted aspartic proteases as virulence factors of Candida species. Biol. Chem. 2002, 383, 1087-1093. [CrossRef]

55. Cvetkovic, R.S.; Goa, K.L. Lopinavir/ritonavir: A review of its use in the management of HIV infection. Drugs 2003, 63, 769-802. [CrossRef]

56. Hermann, J.C.; Ghanem, E.; Li, Y.; Raushel, F.M.; Irwin, J.J.; Shoichet, B.K. Predicting substrates by docking high-energy intermediates to enzyme structures. J. Am. Chem. Soc. 2006, 128, 15882-15891. [CrossRef]

57. Jorgensen, W.L. Efficient drug lead discovery and optimization. Acc. Chem. Res. 2009, 42, 724-733. [CrossRef]

58. Calugi, C.; Guarna, A.; Trabocchi, A. Insight into the structural similarity between HIV protease and secreted aspartic protease-2 and binding mode analysis of HIV-Candida albicans inhibitors. J. Enzyme Inhib. Med. Chem. 2013, 28, 936-943. [CrossRef]

59. Mastrolorenzo, A.; Rusconi, S.; Scozzafava, A.; Barbaro, G.; Supuran, C. Inhibitors of HIV-1 Protease: Current State of the Art 10 Years after their Introduction. From Antiretroviral Drugs to Antifungal, Antibacterial and Antitumor Agents Based on Aspartic Protease Inhibitors. Curr. Med. Chem. 2007, 14, 2734-2748. [CrossRef]

60. Kumar, S.P.; Kulkarni, V.M. Insights into the selective inhibition of Candida albicans secreted aspartyl protease: A docking analysis study. Bioorganic Med. Chem. 2002, 10, 1153-1170. [CrossRef]

61. Dostál, J.; Brynda, J.; Hrušková-Heidingsfeldová, O.; Pachl, P.; Pichová, I.; Řezáčová, P. The crystal structure of protease Sapp1p from Candida parapsilosis in complex with the HIV protease inhibitor ritonavir. J. Enzym. Inhib. Med. Chem. 2011, 27, 160-165. [CrossRef] [PubMed]

62. Gruber, A.; Speth, C.; Lukasser-Vogl, E.; Zangerle, R.; Borg-von Zepelin, M.; Dierich, M.P.; Würzner, R. Human immunode-ficiency virus type 1 protease inhibitor attenuates Candida albicans virulence properties in vitro. Immunopharmacology 1999, 41, 227-234. [CrossRef]

63. Blasi, E.; Colombari, B.; Orsi, C.F.; Pinti, M.; Troiano, L.; Cossarizza, A.; Esposito, R.; Peppoloni, S.; Mussini, C.; Neglia, R. The human immunodeficiency virus (HIV) protease inhibitor indinavir directly affects the opportunistic fungal pathogen Cryptococcus neoformans. FEMS Immunol. Med. Microbiol. 2004, 42, 187-195. [CrossRef]

64. Valle, R.S.; Ramos, L.S.; Reis, V.J.; Ziccardi, M.; Dornelas-Ribeiro, M.; Sodré, C.L.; Branquinha, M.H.; Santos, A.L.S. Trichosporon asahii secretes a 30-kDa aspartic peptidase. Microbiol. Res. 2017, 205, 66-72. [CrossRef] 
65. Palmeira, V.F.; Kneipp, L.F.; Alviano, C.S.; Santos, A.L.S. Secretory aspartyl peptidase activity from mycelia of the human fungal pathogen Fonsecaea pedrosoi: Effect of HIV aspartyl proteolytic inhibitors. Res. Microbiol. 2006, 157, 819-826. [CrossRef] [PubMed]

66. Palmeira, V.F.; Goulart, F.R.V.; Granato, M.Q.; Alviano, D.S.; Alviano, C.S.; Kneipp, L.F.; Santos, A.L.S. Fonsecaea pedrosoi Sclerotic Cells: Secretion of Aspartic-Type Peptidase and Susceptibility to Peptidase Inhibitors. Front. Microbiol. 2018, 9, 1383. [CrossRef] [PubMed]

67. Granato, M.Q.; Sousa, I.S.; Rosa, T.L.S.A.; Gonçalves, D.S.; Seabra, S.H.; Alviano, D.S.; Pessolani, M.C.V.; Santos, A.L.S.; Kneipp, L.F. Aspartic peptidase of Phialophora verrucosa as target of HIV peptidase inhibitors: Blockage of its enzymatic activity and interference with fungal growth and macrophage interaction. J. Enzym. Inhib. Med. Chem. 2020, 35, 629-638. [CrossRef] [PubMed]

68. Gehrt, A.; Peter, J.; Pizzo, P.A.; Walsh, T.J. Effect of increasing inoculum sizes of pathogenic filamentous fungi on MICs of antifungal agents by broth microdilution method. J. Clin. Microbiol. 1995, 33, 1302-1307. [CrossRef]

69. Lass-Flörl, C.; Speth, C.; Kofler, G.; Dierch, M.P.; Gunsilius, E.; Würzner, R. Effect of increasing inoculum sizes of Aspergillus hyphae on MICs and MFCs of antifungal agents by broth microdilution method. Int. J. Antimicrob. Agents 2003, 21, 229-233. [CrossRef]

70. Lerner, C.G.; Goldman, R.C. Stimuli that induce production of Candida albicans extracellular aspartyl proteinase. J. Gen. Microbiol. 1993, 139, 1643-1651. [CrossRef]

71. Hube, B.; Monod, M.; Schofield, D.A.; Brown, A.J.; Gow, N.A. Expression of seven members of the gene family encoding se-cretory aspartyl proteinases in Candida albicans. Mol. Microbiol. 1994, 14, 87-99. [CrossRef] [PubMed]

72. Mata-Essayag, S.; Magaldi, S.; Hartung de Capriles, C.; Deibis, L.; Verde, G.; Perez, C. "In vitro" antifungal activity of protease inhibitors. Mycopathologia 2001, 152, 135-142. [CrossRef]

73. Cordeiro, R.D.A.; Serpa, R.; Mendes, P.B.L.; Evangelista, A.J.D.J.; Andrade, A.R.C.; Franco, J.D.S.; Pereira, V.D.S.; De Alencar, L.P.; Oliveira, J.; De Camargo, Z.P.; et al. The HIV aspartyl protease inhibitor ritonavir impairs planktonic growth, biofilm formation and proteolytic activity in Trichosporon spp. Biofouling 2017, 33, 640-650. [CrossRef] [PubMed]

74. Brilhante, R.S.; Caetano, É.P.; Riello, G.B.; Guedes, G.M.; Castelo-Branco, D.D.S.; Fechine, M.A.; Oliveira, J.S.; Camargo, Z.P.; Mesquita, J.R.; Monteiro, A.J.; et al. Antiretroviral drugs saquinavir and ritonavir reduce inhibitory concentration values of itraconazole against Histoplasma capsulatum strains in vitro. Braz. J. Infect. Dis. 2016, 20, 155-159. [CrossRef]

75. Lin, X.; Alspaugh, J.A.; Liu, H.; Harris, S. Fungal Morphogenesis. Cold Spring Harb. Perspect. Med. 2014, 5, a019679. [CrossRef] [PubMed]

76. Riquelme, M.; Aguirre, J.; Bartnicki-García, S.; Braus, G.H.; Feldbrügge, M.; Fleig, U.; Hansberg, W.; Herrera-Estrella, A.; Kämper, J.; Kück, U.; et al. Fungal Morphogenesis, from the Polarized Growth of Hyphae to Complex Reproduction and Infection Structures. Microbiol. Mol. Biol. Rev. 2018, 82, 2. [CrossRef] [PubMed]

77. Basso, V.; D’Enfert, C.; Znaidi, S.; Bachellier-Bassi, S. From Genes to Networks: The Regulatory Circuitry Controlling Candida albicans Morphogenesis. Curr. Topics Microbiol. Immunol. 2018, 422, 61-99. [CrossRef]

78. Kadosh, D. Regulatory mechanisms controlling morphology and pathogenesis in Candida albicans. Curr. Opin. Microbiol. 2019, 52, 27-34. [CrossRef]

79. Cenci, E.; Francisci, D.; Belfiori, B.; Pierucci, S.; Baldelli, F.; Bistoni, F.; Vecchiarelli, A. Tipranavir exhibits different effects on opportunistic pathogenic fungi. J. Infect. 2008, 56, 58-64. [CrossRef]

80. Margolis, A.M.; Heverling, H.; Pham, P.A.; Stolbach, A. A review of the toxicity of HIV medications. J. Med. Toxicol. 2014, 10, 26-39. [CrossRef]

81. Guaraldi, G.; Stentarelli, C.; Zona, S.; Santoro, A. HIV-Associated Lipodystrophy: Impact of Antiretroviral Therapy. Drugs 2013, 73, 1431-1450. [CrossRef] [PubMed]

82. Graef, M. Lipid droplet-mediated lipid and protein homeostasis in budding yeast. FEBS Lett. 2018, 592, 1291-1303. [CrossRef] [PubMed]

83. Garcia-Rubio, R.; de Oliveira, H.C.; Rivera, J.; Trevijano-Contador, N. The fungal cell wall: Candida, Cryptococcus, and Aspergillus species. Front. Microbiol. 2019, 10, 2993. [CrossRef]

84. Rollenhagen, C.; Mamtani, S.; Ma, D.; Dixit, R.; Eszterhas, S.; Lee, S.A. The Role of Secretory Pathways in Candida albicans Pathogenesis. J. Fungi 2020, 6, 26. [CrossRef] [PubMed]

85. Rapala-Kozik, M.; Bochenska, O.; Zajac, D.; Karkowska-Kuleta, J.; Gogol, M.; Zawrotniak, M.; Kozik, A. Extracellular proteinases of Candida species pathogenic yeasts. Mol. Oral Microbiol. 2018, 33, 113-124. [CrossRef] [PubMed]

86. Cassone, A.; De Bernardis, F.; Torosantucci, A.; Tacconelli, E.; Tumbarello, M.; Cauda, R. In vitro and In vivo Anticandidal Activity of Human Immunodeficiency Virus Protease Inhibitors. J. Infect. Dis. 1999, 180, 448-453. [CrossRef]

87. Monari, C.; Pericolini, E.; Bistoni, G.; Cenci, E.; Bistoni, F.; Vecchiarelli, A. Influence of Indinavir on Virulence and Growth of Cryptococcus neoformans. J. Infect. Dis. 2005, 191, 307-311. [CrossRef]

88. Sidrim, J.J.; Perdigão-Neto, L.V.; Cordeiro, R.A.; Brilhante, R.S.; Leite, J.J.; Teixeira, C.E.; Monteiro, A.J.; Freitas, R.M.; Ribeiro, J.F.; Mesquita, J.R.; et al. Viral protease inhibitors affect the production of virulence factors in Cryptococcus neoformans. Can. J. Microbiol. 2012, 58, 932-936. [CrossRef]

89. Staniszewska, M.; Monika, S. Virulence Factors in Candida species. Curr. Protein Pept. Sci. 2020, 21, 313-323. [CrossRef]

90. De Mello, T.P.; Ramos, L.D.S.; Braga-Silva, L.A.; Branquinha, M.H.; Santos, A.L.S. Fungal Biofilm-A Real Obstacle against an Efficient Therapy: Lessons from Candida. Curr. Top. Med. Chem. 2017, 17, 1987-2004. [CrossRef] 
91. Tsang, C.S.P.; Hong, I.; Tsang, P.C.S. HIV protease inhibitors differentially inhibit adhesion of Candida albicans to acrylic surfaces. Mycoses 2009, 53, 488-494. [CrossRef] [PubMed]

92. Bektić, J.; Lell, C.P.; Fuchs, A.; Stoiber, H.; Speth, C.; Lass-Flörl, C.; Borg-von Zepelin, M.; Dierich, M.P.; Würzner, R. HIV protease inhibitors attenuate adherence of Candida albicans to epithelial cells in vitro. FEMS Immunol. Med. Microbiol. 2001, 31, 65-71. [CrossRef]

93. Zepelin, M.B.-V.; Meyer, I.; Thomssen, R.; Würzner, R.; Sanglard, D.; Telenti, A.; Monod, M. HIV-Protease Inhibitors Reduce Cell Adherence of Candida albicans Strains by Inhibition of Yeast Secreted Aspartic Proteases. J. Investig. Dermatol. 1999, 113, 747-751. [CrossRef] [PubMed]

94. Korting, H.C.; Schaller, M.; Eder, G.; Hamm, G.; Böhmer, U.; Hube, B. Effects of the Human Immunodeficiency Virus (HIV) Proteinase Inhibitors Saquinavir and Indinavir on In vitro Activities of Secreted Aspartyl Proteinases of Candida albicans Isolates from HIV-Infected Patients. Antimicrob. Agents Chemother. 1999, 43, 2038-2042. [CrossRef]

95. Lipke, P.N. What We Do Not Know about Fungal Cell Adhesion Molecules. J. Fungi 2018, 4, 59. [CrossRef]

96. Segal, E.; Frenkel, M. Experimental In vivo Models of Candidiasis. J. Fungi 2018, 4, 21. [CrossRef]

97. Mencacci, A.; Spaccapelo, R.; Del Sero, G.; Enssle, K.H.; Cassone, A.; Bistoni, F.; Romani, L. CD4+ T-helper-cell responses in mice with low-level Candida albicans infection. Infect. Immun. 1996, 64, 4907-4914. [CrossRef]

98. Pericolini, E.; Cenci, E.; Monari, C.; Perito, S.; Mosci, P.; Bistoni, G.; Vecchiarelli, A. Indinavir-treated Cryptococcus neoformans promotes an efficient antifungal immune response in immunosuppressed hosts. Med. Mycol. 2006, 44, 119-126. [CrossRef] [PubMed]

99. Normile, T.G.; Bryan, A.M.; Del Poeta, M. Animal models of Cryptococcus neoformans in identifying immune parameters associated with primary infection and reactivation of latent infection. Front. Immunol. 2020, 11, 581750. [CrossRef] [PubMed]

100. Cassone, A.; Tacconelli, E.; De Bernardis, F.; Tumbarello, M.; Torosantucci, A.; Chiani, P.; Cauda, R. Antiretroviral Therapy with Protease Inhibitors Has an Early, Immune Reconstitution-Independent Beneficial Effect on Candida Virulence and Oral Candidiasis in Human Immunodeficiency Virus-Infected Subjects. J. Infect. Dis. 2002, 185, 188-195. [CrossRef]

101. De Bernardis, F.; Tacconelli, E.; Mondello, F.; Cataldo, A.; Arancia, S.; Cauda, R.; Cassone, A. Anti-retroviral therapy with protease inhibitors decreases virulence enzyme expression in vivo by Candida albicans without selection of avirulent fungus strains or decreasing their anti-mycotic susceptibility. FEMS Immunol. Med. Microbiol. 2004, 41, 27-34. [CrossRef]

102. Cassone, A.; Cauda, R. HIV proteinase inhibitors: Do they really work against Candida in a clinical setting? Trends Microbiol. 2002, 10, 177-178. [CrossRef]

103. Eldesouky, H.E.; Salama, E.A.; Lanman, N.A.; Hazbun, T.R.; Seleem, M.N. Potent Synergistic Interactions between Lopinavir and Azole Antifungal Drugs against Emerging Multidrug-Resistant Candida auris. Antimicrob. Agents Chemother. 2020, 65, e00684-20. [CrossRef]

104. Bustamante, C.; Ochoa, R.; Asela, C.; Muskus, C. Repurposing of known drugs for leishmaniasis treatment using bioinfor-matic predictions, in vitro validations and pharmacokinetic simulations. J. Comput. Aided Mol. Des. 2019, 33, 845-854. [CrossRef] [PubMed]

105. Nosengo, N. Can you teach old drugs new tricks? Nat. Cell Biol. 2016, 534, 314-316. [CrossRef] [PubMed]

106. Gajdács, M.; Spengler, G. The role of drug repurposing in the development of novel antimicrobial drugs: Non-antibiotic phamacological agents as quorum sensing-inhibitors. Antibiotics 2019, 8, 270. [CrossRef]

107. Stragliotto, G.; Pantalone, M.R.; Rahbar, A.; Söderberg-Nauclér, C. Valganciclovir as Add-On to Standard Therapy in Secondary Glioblastoma. Microorganisms 2020, 8, 1471. [CrossRef] [PubMed]

108. Quezada, H.; Martínez-Vázquez, M.; López-Jácome, E.; González-Pedrajo, B.; Andrade, A.; Fernández-Presas, A.M.; Tovar-García, A.; García-Contreras, R. Repurposed anti-cancer drugs: The future for anti-infective therapy? Expert Rev. Anti-Infect. Ther. 2020, 18, 609-612. [CrossRef] 